\title{
ELINOR OSTROM GOES TO OUTER SPACE - AN ASSOCIATION OF SPACE APPROPRIATORS
}

\author{
Shane Chaddha*
}

Before 2009, the literature on space law simply alleged that the growing population of space debris congesting near-Earth orbits is analogous to Garrett Hardin's 'Tragedy of the Commons'. These works, however, failed to illustrate how, if at all, the metaphorical model fits the actual situation and, in turn, explain the challenges involved to address the debris problem ${ }^{1}$. The implication was that Earth's near orbits is a 'common-pool resource' (CPR) that would suffer from the hypothesised 'tragedies' like all natural resources held in common; that is to say, the environmental degradation and eventual ruin of the resource. To address these concerns, this author has elsewhere scrutinised Hardin's works and commons solutions in the context of the space debris problem, verifying the arguments from earlier commentators that near-Earth orbits is a 'Space Commons' that is susceptible to environmental degradation caused by rational, opportunistically space actors misusing and overexploiting the limited natural resources. An attempt to determine the appropriateness and feasibility of applying Hardin's commons prescriptions to avert the 'tragedy' by converting the institutional arrangement of outer space from the existing common-property regime to either a private-property or public- property system has also been undertaken. However, challenging the conventional wisdom postulated by Hardin and his disciples is Elinor Ostrom, who was awarded the 2009 Nobel Prize in Economic Sciences for her analyses and works in economic governance $^{2}$. Supported by empirical evidence, she argues for 'polycentric governance', or 'community-based governance' ${ }^{3}$. Under certain conditions community users of the CPR could effectively promote and maintain the long-term preservation of the resource for the benefit of both present and future generations by constructing their regime framework; hereby minimising or even eliminating the necessity for intervention from the government or some external authority.

To complete this inquiry for alternative institutional arrangement to govern outer space, this Paper considers Ostrom's works to yield insights if her framework for institutional design could provide a robust governance regime that promotes the optimal management and long-term safety and sustainability of the Space Commons for current and future space appropriators. To that end, this Paper is divided into three

\footnotetext{
PhD Candidate from the School of Law, University of Manchester (UK). LLB from the School of Law, University of the West of England, Bristol (UK).

${ }^{1}$ See, for example: Roberts, L.D. A Lost Connection: Geostationary Satellite Network and the International Telecommunications Union. Berkeley Technology Journal Law. 2000, Vol. 15, pp. 1095 1144 at footnote 135; Roberts, L.D. Addressing the problem of orbital space debris: Combining International Regulatory and Liability Regime. Boston College International \& Comparative Law. 1992, Vol. 15, pp. $51-73$ at pp. 58 - 59; and Sreejith, S.G. Whither International Thither Space Law: A Discipline in Transition. California Western International Law Journal. Vol. 38, pp. $331-417$ at p. 409.

${ }^{2}$ BBC News. First woman wins economic Nobel. BBC News. October $12^{\text {th }}, 2009$. Available from: http://news.bbc.co.uk/1/hi/business/8302662.stm. Date Accessed: 12/10/2009; and Tierney, J. The NonTragedy of the Commons. The New York Times. October 15, 2009. Available from:

http://tierneylab.blogs.nytimes.com/2009/10/15/the-non-tragedy-of-the-commons/. Date Accessed: $15 / 10 / 2009$.

${ }^{3}$ Ostrom, E. 1990. Governing the Commons: The Evolution of Institutions for Collective Action. Cambridge University Press: Cambridge.
} 
parts. Parts One and Two, respectively, scrutinise Hardin's 'Tragedy of the Commons' and Ostrom's 'design principles'. They examine the strengths and weaknesses of each author's institutional solutions to control resource users from acting and behaving opportunistically in their utility of the commons and appropriation of its limited resource units in order to avert the environmental degradation and possible ruin of small-scale natural resources. Part Two also considers the reasons why many commentators since 1990 have departed from the conventional wisdom under the Hardinian model to find Ostrom's institutional arrangement of "community-based governance" as a compelling alternative to Hardin's prescriptions for robust and sustainable CPR regimes. Part Three applies Ostrom's design principles to the Earth's near orbits and the debris problem, determining the appropriateness and feasibility of adopting Ostrom's framework to provide an alternative governance regime for the Space Commons.

\section{Part One - A Scrutiny of Hardin's 'Tragedy of the Commons'}

\subsection{The Hardinian Model}

In his hypothetical thesis of the 'Tragedy of the Commons', Garrett Hardin argued that communities sharing land-based common resources are interlocked into an inevitable 'tragedy' that would lead to the ruin of all users as well as the environmental destruction of that commons. Instead of wealth for all; there would be wealth for none. The 'tragedy' occurs because the institutional arrangement for that resource is a common-property regime. Hardin postulates that such governance system permits rational actors to act and behave individualistically for their own short-term interests to the detriment of the long-term collective interests of the remaining resources users. These selfish actors lack the incentives to contribute to the creation and maintenance of the resource and, as a consequence, act in ways which not only leads to the depletion of the limited resources units but also the degradation of that commons. As a result, all members of the community are left with outcomes which are suboptimal to what they could have obtained by acting and behaving in a cooperative manner. According to Hardin, the possibility of users accepting voluntary constraints to limit their appropriating activities of the resource units is not feasible: 'With distribution systems, as with individual morality, good intentions are no substitute for good performance' ${ }^{4}$. He claims that the long-term reliance of such restraint mechanisms is susceptible to the problem of 'free-riding', and would be selfeliminating ${ }^{5}$. An individual user, who is attracted to the moral plea to limit his exploitative activities in order to minimise the effects of environmental deterioration on the CPR, would later discover that his conservative actions does not confer him with any benefits. Instead, the increase in the availability of the resource units rewards self-interested users while the externalities from their overuse are still borne by him. The endeavours of that single actor to preserve the commons resource for the collective interest of the present and future community is thereby frustrated ${ }^{6}$. Freeriders shall continue to exercise their communal rights and behave opportunistically

\footnotetext{
${ }^{4}$ Hardin, G. Commentary: Living on a Lifeboat. BioScience. 1974, Vol. 24(10), pp. 561 - 588 at p. 562.

${ }^{5}$ Hardin, G. The Tragedy of the Commons. Science. 1968, Vol. 162, pp. $1243-1248$ at pp. $1246-$ 1247; and Soroos, M.S. Garrett Hardin and tragedies of a global commons. In: Dauvergne, P (ed). 2006. Handbook of global environmental politics. Edward Elgar Publishing Limited: Chichester, pp. 35 -50 at p. 36.

${ }^{6}$ The Tragedy of the Commons. Supra, note 5 at p. 1246; and Soroos. Supra, note 5 at p. 36.
} 
when exploiting the resource system ${ }^{7}$; both sets of actors shall suffer a relative fall in their respective incomes, however ${ }^{8}$. To save the commons and avert the tragedy, Hardin prescribes that the institutional arrangement of that resource must undergo a transformation. The common-property regime must be restructured to either a privateproperty or public-property arrangement.

For 40 years after its publication in 1968, the Hardinian 'tragedy' has often been labelled by the academic community has 'seminal' and required reading for all'. Hardin's article has been anthologised in over one hundred books, making it one of the most reprinted article to appear in any scientific article ${ }^{10}$. Economics, sociologists, philosophers and theologians have devoted entire books to explore the meaning and implications of the 'Tragedy of the Commons"'. The 'tragedy of the commons' has been used to describe a number of diverse problems including famine in overpopulated countries, urban crime, government's inability to craft effective fiscal budgets and limit their overspending, and problems of international cooperation ${ }^{12}$. By in large, Hardin's article "has been embraced as a sacred text by scholars and professionals in the practice of designing futures for others and imposing their own economic and environmental rationality on other social systems of which they have incomplete understanding and knowledge" ${ }^{, 13}$. Although regarded as authoritative and seminal text, Hardin's 'Tragedy of the Commons' suffers from many inaccuracies and related-weaknesses. This section examines some of these criticisms justifying why the model has received less favour in contemporary commons literature, and political scientists are avoiding Hardin's commons prescriptions to find alternative solutions to manage CPRs and potential environmental dilemmas.

\subsubsection{Is the 'tragedy' inevitable?}

In his article, as aforesaid, Hardin argued that shared terrestrial-based resources would result to overexploitation and misuse by self-interested users and thus its ultimate environmental destruction ${ }^{14}$. Such outcome, or 'tragedy', is 'inevitable' (emphasis added), and is by virtue of the common-property arrangement governing and managing that resource. Hardin based his thesis on a parable, urging the reader to imagine a pasture in medieval English that is "held in common"15. The italicised expression should not be interpreted in its plain, ordinary meaning. In his essay, Hardin followed the erroneous understanding contained in the literature that commonproperty is the same as open access ${ }^{16}$. However, Hardin corrected his omission. In his

\footnotetext{
${ }^{7}$ Ibid; and Alchian, A.A. and Demsetz, H. The Property Rights Paradigm. The Journal of Economic History. 1973, Vol. 33(1), The Task Economic History, pp. $16-27$ at p. 20.

${ }^{8}$ Soroos. Supra, note 21 at p. 36.

${ }^{9}$ Governing the Commons: The Evolution of Institutions for Collective Action. Supra, note 4 at p. 7 ; and Cox, S.J.B. No Tragedy on the Commons. Environmental Ethics. 1985, Vol. 7, pp. 49 - 61 at p. 50.

${ }^{10}$ Augus, I. Debunking the 'Tragedy of the Commons. Links International Journal of Socialist Renewal. August 24, 2008. Available from: http://links.org.au/node/595. Date Accessed: 30/13/2012.

${ }^{11}$ Cox. Supra, note 9 at p. 50.

${ }^{12}$ Governing the Commons: The Evolution of Institutions for Collective Action. Supra, note 4 at p. 3.

${ }^{13}$ Dr. G.N. Appell cited by Augus. See: Augus. Supra, note 10.

${ }^{14}$ Ostrom, E. The Oxford Companion to Global Change: The Commons. In: Cuff, D and A. Goudie (eds). 2009. Oxford Reference Online: Oxford University Press. Available from: http://www.oxfordreference.com/views/ENTRY.html?subview=Main\&entry=t265.e47 (via

Manchester Library \& Information Service). Date Accessed: 23/10/2009.

${ }^{15}$ The Tragedy of the Commons. Supra, note 5.

${ }^{16}$ Feeny, D., F. Berkes., B.J. McCay., and Acheson, J.M. The Tragedy of the Commons: Twenty-Two Later. Human Ecology. 1990. Vol. 18(1), pp. 1 - 19 at p. 5.
} 
later work entitled "Extension of 'The Tragedy of the Commons", Hardin writes: 'To judge from the critical literature, the weightiest mistake in my synthesizing paper was the omission of the modifying adjective "unmanaged." In correcting this omission, one can generalize the practical conclusion in this way: "A 'managed commons' describes either socialism or the privatism of free enterprise. Either one may work; either one may fail: 'The devil is in the details.' But with an unmanaged commons, you can forget about the devil: As overuse of resources reduces carrying capacity, ruin is inevitable"" ${ }^{17}$. In his original essay in 1968, Hardin was accordingly describing an open access pasture. In other words, there were no well-defined property rights controlling access to and use of the pasture. It was owned by no one, and was free and open to all graze their cattle and generate an income thereon ${ }^{18}$. He assumed that commons in rural England had no enforceable rules or some other restraints from the number of cattle each resident is permitted to keep on the common pasture ${ }^{19}$. Taking the view that each herdsman would try to keep as many cattle as possible, Hardin then examined when the 'tragedy' falls on this common land from the point of view of a rational, yet self-interested, herder. Each resident is motivated to maximise his gain for profit and such benefit by adding more cattle on the commons. That user receives all of the proceeds from the sale of each additional cattle, and suffers a fraction of the cost from the environmental decline caused from the increased grazing. Motivated by the short-term financial benefit from the sale of the additional cattle than the longterm sustainable use of the grazing lands ${ }^{20}$, the rational herdsman therefore concludes 'that the only sensible course for him to pursue is to add another animal to his herd. And another; and another ... ${ }^{21}$. This decision and behaviour by that single herder is shared and repeated by each and every actor using that pastures. The process of adding more cattle continues until the pasture's grazing availability is exhausted; thus, leading to the destruction of the very land the resident depend ${ }^{22}$ which becomes of little or no further use to anyone ${ }^{23}$. 'Therein lies the tragedy', Hardin concludes that: 'Each man is locked into a system that compels him to increase his herd without limits - in a world that is limited. Ruin is the destination toward which all men rush, each pursing his own best interest in a society that believes in the freedom of the commons. Freedom in a commons brings ruin to all ${ }^{24}$.

Notwithstanding the claim that the 'tragedy' is inevitable, Hardin provides no empirical evidence to substantiate his conclusions. He misapplied the fable and misunderstood conditions of medieval English commons. During the 1970s and 1980s, many historians and anthropologists have criticised Hardin's historical descriptions for being historical inaccurate ${ }^{25}$. Prior to 1968, many scholars such Friedrich Engles had empirical studies of community-based regimes in parts of pre-

\footnotetext{
${ }^{17}$ Hardin, G. Extension of 'The Tragedy of the Commons'. Science. May 1, 1998. Vol. 280(5364), pp. $682-683$.

${ }^{18}$ Soroos. Supra, note 5 at pp. 35 - 50 at p. 36.

${ }^{19}$ Ibid; and Vogler, J. Studying the global commons: governance without politics? In: Dauvergne, P (ed). 2006. Handbook of global environmental politics. Edward Elgar Publishing Limited: Chichester, pp. $51-63$ at p. 51 .

${ }^{20}$ Studying the global commons: governance without politics? Ibid.

${ }^{21}$ The Tragedy of the Commons. Supra, note 5 at p. 1244.

${ }^{22}$ Ibid.

${ }^{23}$ Soroos. Supra, note 5 at p. 51.

${ }^{24}$ The Tragedy of the Commons. Supra, note 5 at p. 1244.

${ }^{25}$ Augus, I. Once again on 'The myth of the Tragedy of the Commons': a reply to criticisms and questions. Links International Journal of Socialist Renewal. November $3^{\text {rd }}$, 2008. Available from: http://links.org.au/node/725. Date Accessed: 30/13/2012.
} 
capitalist Germany where resources users successfully managed and controlled potential environmental problems through the implementation of appropriate and viable rules ${ }^{26}$. Engles' findings of successful self-regulation by resource members themselves were later supported by the academic community. Cox, for example, writes: '[W] hat existed in fact was not a 'tragedy of the commons' but rather a triumph: that for hundreds of years - and perhaps thousands, although written records do not exist to prove the longer era - land was managed successfully by communities ${ }^{27}$. She argues that Hardin's fable of an English commons were significantly different to that in modern times. The English commons was not 'openaccess' for individuals belonging to the general public but the rights of access and use were limited to those who inherited or were granted such rights. Furthermore, the English commons was not unregulated. There are accounts of commons users developing and enforcing rules - known as "stinting" - which restricted the number of cattle the herdsman's could keep and graze on the pasture and were based on the limited holding capacity of the resource. Abuse of the commons usually took in the form of a private-property regime, whereby wealthier landowners deliberately put too many animals onto the pasture to the detriment of the poorer commoners, who could do little to provide winter feed, as a means of weakening their position in disputes over the enclosed common lands in order to evict them ${ }^{28}$. From her findings, Cox concludes that the environmental decline of medieval English commons were not the result of unlimited access as postulated by Hardin, but rather the result of the historical forces of the industrial revolution, agrarian reform, and improved agricultural practices ${ }^{29}$.

\subsubsection{Are human beings selfish and unchanging?}

Hardin's application of applied behavioural economic theory and theoretical game theory has led to another mistaken assumption that human beings are selfish and unchanging; that their self-interest would mean that individuals would act and behave in a manner that advances or maximises their own benefit with little to no regard to the impact their outcomes produces on society as a whole ${ }^{30}$. In his fable, Hardin asserts that it is the aim of every herdsman to expand their cattle on the pasture: 'It is to be expected that each herdsman will try to keep as many cattle as possible on the commons. ... As a rational being, each herdsman seeks to maximize his gain'. Hardin's assertion that commons users would inevitably act and behave individualistically is unmerited. It goes against empirical findings showing that humans are social beings. Although humans act and behave selfishly when as an individual, they can yet act altruistically and for the common good when acting as a collective unit ${ }^{31}$. Furthermore, there would have been practical limitations inhibiting the herdsman to behave in the manner Hardin described: he could not have done so unless certain conditions existed. As Augus writes, '[t]here would have to be a market for the cattle, and he would have to be focused on producing for that market, not for local consumption. He would have to have enough capital to buy the additional cattle

\footnotetext{
${ }^{26}$ The Myth of the Tragedy of the Commons. Supra note 25.

${ }^{27}$ Cox. Supra, note 9 at p. 50.

${ }^{28}$ Cox. Supra, note 9 at pp. 56 - 59; and The Myth of the Tragedy of the Commons. Supra, note 24

${ }^{29}$ Cox. Supra, note 9 at p. 50.

${ }^{30}$ The Myth of the Tragedy of the Commons. Supra, note 25.

${ }^{31}$ Habito, C.F. Ostroms Nobel: Shedding paradigms. Philippine Daily Inquirer. October 29, 2009. Section: Business Page: 2.
} 
and the fodder they would need in winter. He would have to be able to hire workers to care for the larger herd, build bigger barns, etc. And his desire for profit would have to outweigh his interest in the long-term survival of his community ${ }^{32}$.

\subsection{3. 'Tragedies' of Hardin's Commons Solutions}

Another weakness concerns the solutions Hardin prescribes in order to save the commons and avert the 'tragedy'. He presents them as though they are panaceas to save the resource system from environmental destruction, and excludes the possibility that alternative institutional arrangements exist and can successfully manage the commons. From a scrutiny of his article, it is apparent that Hardin provides no evidence to support his claim that environmental ruin of the shared resources is inevitable under a CPR arrangement. As seen above, empirical research dated before the publication of the 'Tragedy of the Commons' have described situations where community members of scale-small resources have successfully established selfgoverning institutions that were robust and constrained the behaviour of resources actors from acting opportunistically through their consumptive appropriation of the available resource units, which in turn averted the 'tragedy of the commons', and promoted the long-term sustainability of the resources. Furthermore, there is no objective reasoning explaining how either a private property or public property system would avoid the tragedy. Hardin simply writes: 'We must admit that our legal system of private property plus inheritance is unjust - but we put up with it because we are not convinced, at the moment, that anyone has invented a better system. The alternative of the commons is too horrifying to contemplate. Injustice is preferable to total ruin ${ }^{33}$. He further states that change of the existing common-property arrangement must be instituted by 'whatever force may be required to make the change stick ${ }^{34}$. In other words, "if ruin is to be avoided in a crowded world, people must be responsive to a coercive force outside their individual psyches, a "Leviathan", to use Hobbes' terms ${ }^{, 35}$. As a disciple of the 'Prisoners' Dilemma' and the 'Rational Choice Theory' which influenced his hypothesis, Hardin blindly follows the conventional wisdom that a 'Leviathan', or 'coercive force', through an external entity is necessary to internalise the environmental costs produced by the overexploitation and misuse of the commons from its rational, yet selfish users ${ }^{36}$. Albeit he concedes that such third-party regulatory control can be suboptimal, Hardin takes the view that such shortcomings should be tolerated since the alternative outcome under a common-property regime is 'too horrifying to contemplate, ${ }^{37}$. The logic of Hardin's commons solutions is the policy prescription that privatisation or nationalisation can provide a robust institutional regime that successfully manages and promotes the sustainability of the resource. According to the Hardinian school of thought, these property-rights systems provide incentives for private owners and regulatory agencies to internalise the externalities generated from the exploitation of

\footnotetext{
${ }^{32}$ The Myth of the Tragedy of the Commons. Supra, note 25.

${ }^{33}$ The Tragedy of the Commons. Supra, note 5 at p. 1247.

${ }^{34}$ Hardin, G. Political requirements for the preserving our common heritage. In: Brokaw, H.P. (ed.)

Wildlife and America. Council on Environmental Quality: Washington, D.C., pp. 310 - 317 at p. 314.

${ }^{35}$ Political requirements for the preserving our common heritage. Ibid, p. 314.

${ }^{36}$ Young, O.R. Land use, environmental change, and sustainable development: the role of institutional diagnostics. Supra, 36 at p. $68-76$.

${ }^{37}$ The Tragedy of the Commons. Supra, note 5 at p. 1247.
} 
the resource by prescribing rules restraining accessibility and utility ${ }^{38}$. Proponents of private property regimes take the view that the allocation of ownership rights over areas to individual actors would instil 'intrinsic responsibility', which in turn would lead to sustainable choice-making outcomes being made by those users ${ }^{39}$. In other words, being solely accountable for those externalities from the overexploitation and misuse over the assigned area should encourage the private owner to exercise good decision-making choices. In order to preserve the allocated region for his future generations, the actor would behave conservatively and act efficiently by ensuring that his appropriation acts are within the holding and regenerative capabilities of his enclosed area ${ }^{40}$. Private rights, therefore, could be a catalyst promoting 'environmental behavioural reform', where a rational private owner would behave conversably over his vested property and act according to his long-term economic interest for the long-term benefits. The net return for this behavioural change is the sustainable management, and the owner's future generations' enjoyment in the use, of the enclosed area. Proponent of the public property system, on the hand, would argue that the government or some public agency should hold the shared resources on trust, acting as a trustee that is vested the authority to manage the system, to regulate access and govern operational use and the activities undertaken by users in order to ensure its environmental preservation for current and future beneficiaries. The rationale for public management is the presumption that rational actors cannot be trusted to constraint their own appropriation activities, and to cooperatively behave and act for the mutual benefit of the remaining users for long-term environmental sustainability of the shared resource. An external actor is necessary to develop a system of rules and decision-making procedures to regulate access and oversee use, and to protect actors themselves from their own destructive behaviours and actions ${ }^{41}$. However, an underlying assumption in Hardin's hypothesis is that these incentives would be absent or weak for other property-rights regimes ${ }^{42}$. Extensive empirical studies have, however, unequivocally found that the proposed policy prescriptions would not always lead to the sustainable management of the resource ${ }^{43}$. An appraisal of Young's works shall show that, paradoxically, such systems of private property or public property can generate their own 'tragedies' which have been known to be equally severe to the 'tragedy of the commons', and be accountable for the number of environmental resource systems that have been ruined following the privatising or nationalising the commons ${ }^{44}$.

\subsubsection{1. 'The Tragedy of Private Property'}

In his works, Young takes the view that the perceived benefits of privatisation of the commons are not quite as simple as the literature of natural resources would

\footnotetext{
${ }^{38}$ Feeny et al. Supra, note 16 at p. 15.

${ }^{39}$ Soroos, M.S. The Commons and Lifeboat as Guides for International Ecological Policy. International Studies Quarterly. Special Issue on International Politics of Scarcity. 1977, Vol. 21(4), pp. $647-674$ at p. 650 .

${ }^{40}$ The Commons and Lifeboat as Guides for International Ecological Policy. Supra, note 44 at pp. 650 and 668 .

${ }^{41}$ Land use, environmental change, and sustainable development: the role of institutional diagnostics. Supra note 36 at p. 73.

${ }^{42}$ Feeny et al. Supra, note 16 at p. 12.

${ }^{43}$ See, for example: Feeny et al. Supra, note 16.

${ }^{44}$ Land use, environmental change, and sustainable development: the role of institutional diagnostics. Supra, note 36 at p. 71.
} 
convey. He argues that there are three pertinent problems which, if taken together, can lead to the 'tragedy' of the private property that are just worrisome from societal perspective as the tragedy of commons ${ }^{45}$. The first mechanism is what Young calls: 'killing the goose that lays the golden the golden egg'. Here, rational private owners of the enclosed area have short-time horizon and no intention to confer the rights over the property to a later generation. They attribute less value to the benefits they expect to receive in the distant future and more value on the benefits in the immediate future $^{46}$. Under such conditions, these actors would have the incentive to consume the entire resource of its units, invest the proceeds in some alternative goods or services sector that has a higher rate of return, and then sell the land that they have been allocated for some other purpose than originally used. According to Young, this type of strategic behaviour would particularly be appealing in settings '... where the resources in question grow or develop slowly, the owner has a high rate of discount with respect to time, there are investment options that seem likely to produce higher rates of return, and there are few if any public regulations regarding the destruction of the resource itself ${ }^{47}$.

Young's second criticism is that private property regimes fail to consider nonmarket values, favouring those values which only can be commodified or made marketable relatively easily and inexpensively. Many resources systems can be used for wide range of purposes. Conventional use of the resource units may have welldeveloped markets and so the goods and services produced can be easily quantified. The different range of goods and services produced because of alternative uses of the resource, on the other hand, may be harder to commodify and therefore subject to the market forces of supply and demand than products generated from the conventional use. Under such private property- arrangements, owners are incentivised to consumptively use the resource. They are encouraged to favour some uses of the resource which have market value at the expenses of others uses that are nonconsumptive and in turn less profitable and readily marketable. As Young explains, ' $[\mathrm{t}]$ he result, again, is a practice that is costly to society, even though it makes sense from the perspective of the rational owner, ${ }^{48}$.

The third problem that Young identifies is the unintended side effects which are a by-product following the institution of a private property system. He writes: 'Whereas commodification is about the choices that owners make regarding alternative uses of their own resources, unintended side effects or externalities have to do with impacts on the welfare of others flowing from choices about the use of resources $^{, 49}$. Such externalities generated from the appropriation activities on smallscale resource systems can contribute to the environmental consequences at a largerscale, and thus the environmental costs shared by members of society are destined to become even more costly. For example, the destruction of forests can attribute the increase of carbon dioxide emitted into the atmosphere and therefore contribute to global climate change. To address the problem of transboundary pollution, public regulations that impose restrictions on the behaviour of owners or users of private property are required. As Young provides, 'No one likes regulations that are introduced specifically to constrain or limit their activities. But so long as private

\footnotetext{
${ }^{45}$ Governing the Commons: The Evolution of Institutions for Collective Action. Supra, note 4 at p. 34.

${ }^{46}$ Ibid.

${ }^{47}$ Land use, environmental change, and sustainable development: the role of institutional diagnostics. Supra, note 36 at p. 71 .

${ }^{48}$ Ibid, pp. $71-72$.

${ }^{49}$ Ibid, p. 72.
} 
property remains a widespread system of rights governing human-environment relations, rising interdependencies among the members of society will dictate the need to find ways to impose increasingly restrictive rules limiting the freedom of owners of private property to do as they please regarding the use of their property ${ }^{50}$. This reinforces the argument that privatisation alone does not provide a clear-cut solution to deal with collection-action problems and environmental dilemmas affecting natural resource systems.

From the commons literature, another closely-associated side effect with the privatisation of the commons is the 'tragedy of dispossession'. Historical accounts of local commons being privatised illustrate that a large collection of users, who previously enjoyed access to that resource system and appropriation rights of the consumable resource units, were dispossessed ${ }^{51}$. For those who were subsequently excluded, many resource users were better off by deriving greater benefits under the initial CPR regime. As Vogler writes, "[f]or those villagers that did, enclosure solution frequently resulted in destitution and to increasing disparities of wealth, but the effects were offloaded onto the local parish or resulted in bands of 'sturdy beggars' who roamed Elizabethan England"52.

\subsubsection{2. 'The Tragedy of Public Property'}

In his works, Young postulates that there is a tragedy of public property that parallels and is equally severe to the tragedies of the commons and private property. The environmental ruin of natural resources under the management of an external actor is the result of government failures. Young identifies three types of government failures that are most relevant to the tragedy of public property. The first form is referred to as 'gridlock' which occurs in all political systems, and is the result of a breakdown during the policy-making procedures that later manifests in either paralysis or complicated compromises. Paralysis can result at both the legislative level and the executive level where many influential actors or coalitions consisting of influential actors are able to form blocking coalitions but few are in a position to form winning coalitions. The most common outcome in these situations is the strong preference to preserve the status quo; whether such course of action promotes the sustainability of the resource is immaterial. An example of gridlock that Young provides is the inability of the U.S. Senate to ratify the UN Convention on the Law of Sea $1982^{53}$, even though it has had received the support of both the Republican and Democratic presidents and was favoured by the majority of senators ${ }^{54}$. Gridlock may also arise in cases where the development of complicated compromises that work in a political sense but generate consequences which are problematic for the successful governance of human activities on resources ${ }^{55}$.

Another type of government failure that may lead to the tragedy of public domain is corruption. Corruption in this sense means that policies formed provide preferential treatment such as subsidises, reduce tax rates and other benefits which are

\footnotetext{
${ }^{50}$ Ibid, p. 72.

${ }^{51}$ Vogler, J. 2002. The Global Commons: Environmental and Technological Governance. $2^{\text {nd }}$ ed. John and Sons Ltd: Chichester at p. 13.

52 Ibid.

${ }^{53}$ United Nations Convention on the Law of Sea 1982. A/CONF.62/122. October 7, 1982.

${ }^{54}$ Land use, environmental change, and sustainable development: the role of institutional diagnostics. Supra, note 36 at p. 74.

${ }^{55}$ Ibid, p. 74.
} 
in the interest of influential stakeholders who desire to the use of the resource. In exchange, these certain group of users would provide lasting and mutually supportive relationships to executive bodies through lobbies, for example. Such relationships can however pose as a substantial barrier towards sustainability, increasing the difficulty for legislators to change the course of policies which regarded as outdated and inappropriate for effective governance of the resource ${ }^{56}$.

The third type of government failure identified by Young is what he calls 'institutional arthritis'. He explains: 'Unlike gridlock, which results from the inability to create winning coalitions, arthritis results from the entrenchment of defenders of the status quo in legislative settings and the ossification of bureaucracies responsible for the implementation of policies. The result is a form of path dependency leading to the perpetuation of the status quo regardless of the consequences for sustainability, ${ }^{57}$. In other words, the emergence of institutional arthritis, if left unaddressed, gradually results to the declining capacity of public regulators to respond to abrupt changes in a nimble fashion, to engage in 'adaptive governance' to accordingly deal with those problems, and to address longer-term issues affecting the resource in a timely manner ${ }^{58}$.

\subsubsection{Hardin's Metaphor - Pseudo-Science and Its Harmful Use in $\underline{\text { Real-world Situations }}$}

An appraisal of Young's works shows that systems of private property-rights or public property-rights can generate their own 'tragedies' which parallels to the 'tragedy of the commons'. Though each has different conditions which would trigger such its respective occurrence, '....the tragedies of private property and the public domain are every bit as worrisome from the perspective of social welfare as the tragedy of the commons, especially as we endeavour to achieve sustainability in an era of globalization and global environmental change ${ }^{59}$. Accordingly, Hardin's conclusion that 'freedom in the commons brings ruin to all', including his commons solutions that privatisation or nationalisation of a shared terrestrial resources, would lead to its optimal management are unsafe. Empirical evidence demonstrates that such policy recommendations are not universally compatible to real-world situations. There are complex interactions between and among many factors which affect the robustness and effectiveness of institutional arrangements to govern and regulate a natural resource successfully. Such factors include the peculiar physical characteristics of the resource; the prevailing customary norms affecting access and operational use; and the socio-economic conditions. Feeny et al.'s research, for example, illustrates that success in the governance of resource access and uses and actors themselves is not universally contingent with any particular type of propertyrights regime. Common-property, private property, and public property have all been associated both with success and failure ${ }^{60}$. Moreover, it should not be presumed that a 'monocentric regime'; that is a singular institutional arrangement, must be instituted in order to achieve the optimal management of the land-based resource concerned. For such success to be achieved, it might be necessary to develop and implement a 'polycentric regime'; that is a multi-layered governance structure that emerges two or

\footnotetext{
${ }^{56}$ Ibid, p. 74.

${ }^{57}$ Ibid, p. 74.

${ }^{58}$ Ibid, p. 75.

59 Ibid, p. 68.

${ }^{60}$ Feeny et al. Supra, note 16 at p. 12.
} 
more of the conventional property-rights systems discussed, especially where the resource in question is a complex, multi-level system such as a global commons with a complex, multi-level problem ${ }^{61}$. Such institutional approach fosters a comanagement arrangement whereby authority over regulating access and use of the commons resource is vested to more than one entity, and does not exclude resource stakeholders like individuals, communities and non-governmental organisations from working cooperatively with regional authorities and national governments to tackle overexploitation and misuse.

Contrary to some members of the scholarly community, it can be argued that Hardin's thought-experiment is not science per se but pseudo-science ${ }^{62}$. The model is insightful but incomplete. The conclusion that 'freedom in the commons brings ruin to all' and thus lead to the environmental ruin and destruction of natural resources is contingent on a number of unproved assumptions. Hardin's hypothetical metaphor is therefore overly-simplistic. It overlooks the importance on the capacity of institutional arrangements to exclude unauthorised actors accessing and using the resource, and regulate authorised actors' appropriation activities. The model moreover neglects the implications of socio-economic, political and cultural factors on the decision-making choices and the patterns of behaviour and actions resource users exhibit in their dayto-day operational use. From the commons literature, empirical studies have found that a positive correlation in terms of the property-rights regime governing the resources and the resulting outcomes that Hardin argues- that is, the self-serving behaviour of rational actors to overexploit and misuse the resource and the inevitable consequence of the 'tragedy of the commons' - cannot be drawn. The Hardinian hypothesis accordingly breaks down in real-world situations - "no single metaphor can tell the full story ${ }^{63}$. Despite this, the 'Tragedy of the Commons' is taken as the starting point in institutional approaches to deal with collective-action problems. Consequently, the commons solutions proposed by Hardin are still used today and adopted by policy-makers ranging from national governments, regional authorities through to international organisations like the United Nations in order to support the private ownership and nationalisation of land-based resource systems.

According to post-Hardinian and related political science literature, an underpinning reason why there is still uncritical acceptance with theories of collective action like the 'Tragedy of Commons' and the 'Prisoner's Dilemma' in decisionmaking outcomes can be attributable to the persuasive effects metaphors generate when they are used as models ${ }^{64}$. Lakoff and Johnson take the view that metaphors are '...one of the important tools for trying to comprehend partially what cannot be comprehend totally: our feelings, aesthetic experiences, moral practices, and spiritual

\footnotetext{
${ }^{61}$ Ostrom, E. 2009. A Polycentric Approach for Coping with Climate Change. Background paper to the 2010 World Development Report. Policy Research Working Paper 5095.

${ }^{62}$ Feeny et al. Supra, note 16 at p. 2.

${ }^{63}$ Ibid, pp. $12-14$.

${ }^{64}$ For example, Governing the Commons: The Evolution of Institutions for Collective Action. Supra, note 2 at pp. 7 - 8; Dowding, K. Model or Metaphor? A Critical Review of Policy Network Approach. 1995. Political Studies, Vol. XLIII, pp. 136 - 158; van. Hulst, M.J. The Heart of the Matter: Decision Making Caught in Metaphors. 2005 ECPR Joint Session of Workshops. Paper for Workshops on Metaphors in Political Science. 14-19 April. Granada, Spain. Available from:

http://eis.bris.ac.uk/ potfc/Granada/Papers/Vanhulst.pdf. Date Accessed: 06/02/2013; and Yanow, D. Cognitive Meets Action: Metaphors as Models of and Models for. 2005 ECPR Joint Session of Workshops. Paper for Workshops on Metaphors in Political Science. 14-19 April. Granada, Spain. Available from: http://eis.bris.ac.uk/ potfc/Granada/Papers/Yanow.pdf. Date Accessed: 06/02/2013.
} 
awareness ${ }^{65}$. Whilst they are heuristically useful, the use of metaphors in science is challenging ${ }^{66}$. When models are used as metaphors, the similarity between one or two characteristics in a natural setting and one or two characteristics in a model are usually drawn by the author. By making similarities between settings, the purpose of that metaphorical model is intended to convey information in graphical form ${ }^{67}$. However, such intention cannot be conveyed unless the characteristics between realworld situations and the model are perfect, which leads the author to go far to say that that fit $i s$ the same in both situations ${ }^{68}$. In the context of CPR dilemmas, the effect of such similarities between individuals actor collectively consuming the available resource units in real-world situations with the individual actors suboptimal managing and using the resource in the model, and saying that the real-world setting is an exact fit to the model, the author wishes to invoke the image of the 'Tragedy of the Commons' :'.... an image of helpless individuals caught in an inexorable process of destroying their own resources' (emphasis added) ${ }^{69}$. However, the use of metaphors is always partial ${ }^{70}$. As Jue argues, the same metaphor can be used in a variety of ways, none of which require perfect fit of between the settings concerned, and still provide some utility under specific circumstances, This can be seen with Hardin's 'Tragedy of the Commons' which has been has become part of the conventional wisdom in environmental studies, resource science and policy, economics, ecology, and political science and is featured in a number of textbooks ${ }^{71}$. To that end, it is said that 'metaphoric language seems to produce the opposite effect that scientific language strives for, allowing for the very play of meaning that scientific language seeks to root out in its quest to establish stable and unambiguous meaning, ${ }^{72}$.

Such models can accordingly be so dangerous when they are used metaphorically as the basis for policy-making decisions. They are over-simplified notions of a problem affecting a given arena-setting which can lead to an inadequate understanding of the actual issues involved and, in turn, false policy recommendations being prescribed. For example, in his original essay, Hardin merely asserts that systems of private property or public property rights can save the commons and avert the 'tragedy' but says nothing on how to construct such institutional arrangement to optimise the efficiency of the regime. As Ostrom writes, 'An assertion that central regulation is necessary tell us nothing about the way a central agency should be constituted, what authority it should have, how the limits on its authority should be maintained, how it will obtain information, or how its agents should be selected, motivated to do their work, and have their performances monitored and rewarded or sanctioned. An assertion that the imposition of private property rights is necessary tell us nothing about how that bundle of rights is to be defined, how the various attributes of the goods involved will be measured, who will pay for the costs of excluding nonowners from access, how conflicts over rights will be adjudicated, or how the residual

\footnotetext{
${ }^{65}$ Lakoff and Johnson cited by Jue. See: Jue, M. Playing with Metaphor: The effects, problems, and appeal of using a theater metaphor to frame a neurological understanding of consciousness. Explorations: An Undergraduate Research Journal. 2007, pp. 97 - 110 at p. 97. 
interests of the right-holders in the resource system itself will be organized ${ }^{73}$. Notwithstanding these weakness, policy analyst would relying on models and allegories like the 'Tragedy of the Commons' and 'Prisoner's Dilemma' without critically examining whether the metaphor fits with the actual real-world situations. As Ostrom warns, relying on such metaphors as the foundation for policy advice can lead to results substantially different from those presumed to be likely ${ }^{74}$. This is because '...there are no panaceas in the sense of simple prescriptions that will allow us to avoid the tragedies of commons, private, and public property. The success or effectiveness of specific solutions is normally determined by a combination of conditions occurring in real-world situations, ${ }^{75}$.

\subsection{Part Two - A Scrutiny of Ostrom's Design Principles}

Part One critically examined Garrett's Hardin's hypothetical model called the 'Tragedy of the Commons'. Hardin's metaphorical model of CPRs suffering from this inevitable 'trap' if not owned privately or by a central authority was the conventional wisdom for over 40 years. It was argued however that the Hardinian model is pseudoscience, and could be harmful if used as the foundation of policy-making outcomes for real-world situations. One the one hand, Hardin adopted a number of unproved assumptions in the formulation of his thesis. On the other hand, albeit empirical studies do exist where he is correct, Hardin representing that the 'tragedy' as a universal phenomenon is a significant challenge that goes against findings from field settings.

This Part considers the works of an alternative property-right theorist for a robust and sustainable institutional arrangement that successfully govern commons resources and manages environmental problems. It nominates Elinor Ostrom, who was awarded the 2009 Nobel Prize in Economic Sciences for her analyses and works in economic governance. Having examined Hardin's 'Tragedy of the Commons' and its weaknesses, this section focuses on Ostrom's literature to justify the reasons why later works find her governance approach to CPR management as a compelling alternative to Hardin's. It assesses Ostrom's efforts to contribute to the development of the theory of self-organisation and self-governance through empirically-supported findings. It discusses Ostrom's attempts to explain how it is possible for some communities to optimally govern and mange CPRs and others do not, and identifies the underlying 'design principles' of the institutions used by those communities who successfully sustained their own CPRs over an extended period of time, and why these factors may affect users' actions and behaviours to continue investing time and effort to manage their own resources. This section then thoroughly scrutinises Ostrom's 'design principles', assessing the criticisms on its actual capacity and compatibility to yield a robust and sustainable institutional regime to govern local and global commons resources.

In her book entitled 'Governing the Commons: The Evolution of Institutions for Collective Action', Ostrom challenges the conventional wisdom of the Hardinian model that common-pool resources are trapped in an inevitable environmental 'tragedy', and should be regulated by either central authorities or private owners. She sets a study that explains how groups of individuals in interdependent settings can

\footnotetext{
${ }^{73}$ Governing the Commons: The Evolution of Institutions for Collective Action. Supra, note 3 pp. 22.

${ }^{74}$ Ibid, p. 23.

${ }^{75}$ Governing the Commons: The Evolution of Institutions for Collective Action. Supra, note 3 at pp. 25 -22 .
} 
optimally govern and manage shared natural resources themselves to continuously produce joints benefits when all face the temptation to free-ride, shirk, or otherwise act and behave opportunistically. However, to undertake this inquiry, Ostrom's research approach is very different to that of neo-classical economists such as Hardin and his disciples. She generates her insights and conclusions from actual on-the-field case studies, rather from the application of theoretical models utilised by economists, like game theory, which mistakenly presumes that the actors concerned are homogenous in terms of their capital, skills, cultural views and knowledge of the resource system and its environment. These theories, in addition, assume that human beings are selfish and unchanging; and that their self-interest would mean that individuals would act and behave in a manner that advances or maximises their own benefits with little to no regard to the impact their outcomes produces on society as a whole $^{76}$. Ostrom, on the hand, assumes that individuals are not irrational and act and behave individualistically for their own gain as postulated under the Hardinian 'tragedy', but have sufficient capacity to reason and try to solve problems as effectively as they can. This presumption enables her to combine the literature of scholars interested in institutional arrangements with the strategies used by political scientists for field settings to ascertain what problems individuals are faced in CPR situations, and what factors may incentivise or deter individuals for their efforts to resolve those problems ${ }^{77}$. In fact, with this assumption, Ostrom's empirical findings illustrate that humans, when acting as individual entities, can act and behave opportunistically and in turn wilfully close their minds to the long-term, mutual interests of other resource users for resource sustainability. These same individuals are, nonetheless, capable to act altruistically and voluntarily forgo short-term benefits for the common good providing the community of resource actors cooperate and acting as a collective unit. These actors would make "contingent strategies", than independent strategies. "Contingent strategies" are defined as "... a whole plan of actions that are contingent in the world" . An example of a "contingent strategy" is the 'tit-for-tat' game, whereby an individual would adopt a cooperative strategy in the first round of interaction and then reciprocate the actions and behaviour of others in future rounds ${ }^{79}$. According to Ostrom, because CPR settings extend over time, individuals may make contingent commitments to participate in and comply with the rule-in-use under the communal-property regime providing these individuals believe that other resource members would reciprocate cooperation by behaving and acting in the manner expected, and that the long-term benefits from participation in and observance to the regime outweigh the potential benefits which would otherwise have been generated from independent strategies ${ }^{80}$.

Ostrom, furthermore, goes against the dogma of decision-makers to make policy outcomes concerning institutional reform should be based on metaphorical models, and the dichotomy between Hardin's common solutions as "good" and other types of institutional regimes which are beyond the conventional wisdom as being "bad" in the absence of some on-the-field analyses on the institutional performance of these

\footnotetext{
${ }^{76}$ Heine, J. A Nobel Prize for Political Science. The Hindu. November 14, 2009.

${ }^{77}$ Governing the Commons: The Evolution of Institutions for Collective Action. Supra, note 3 at pp. 25 $-26$.

${ }^{78}$ Governing the Commons: The Evolution of Institutions for Collective Action. Supra, note 3 at pp. 36 -37 .

${ }^{79}$ Axelrod, R. 1984. The Evolution of Cooperation. Basic Books: New York.

${ }^{80}$ Governing the Commons: The Evolution of Institutions for Collective Action. Supra, note 3 at pp. 36

- 37; and Cole, D.H. 2004. Pollution and Property: Comparing Ownership Institutions for

Environmental Property. Cambridge University Press: Cambridge at p. 123.
} 
regimes. As discussed above, she is of the opinion that models are useful in policy analysis when they are well-tailored to the particular problem at hand. Models are however used inappropriately when applied to the study of problematic situations that do not closely fit the assumptions of the model ${ }^{81}$. Through her empirical research, Ostrom finds that where a resource produces a single, valuable resource unit with a high level of predictability known to all participants, it is possible to implement Hardin's commons prescriptions. That is to say, to devise marketable rights or other simple allocation rules that enable individuals to make efficient long-term use of the resource. On the other hand, in CPR situations where the community of users do not know who is in their group, there no feedback is provided on individual actions, and actors cannot communicate with each other would result in the overexploitation of the limited resource units and misuse of the commons itself ${ }^{82}$. In such real-world situations, these group of appropriators '...do worse than game theory predicts and fit the behaviour predicted by Hardin' ${ }^{83}$. Hardin's hypothesised 'tragedy' might also occur when there are one or more external entities, who are stakeholders to the CPR but are outside the community's social-economic system, restrict the autonomy of the community's to craft their own institutions and management policies by imposing their solutions, exerting political power or changing the rules in order to gain an advantage for themselves. Ostrom demonstrates that most common resources are well-managed when those who stand to benefit are close to the resource and to each other. Under certain conditions, the community of small-scale actors can embrace their local knowledge and draw upon their personal familiarity in using the resource to tailor an institutional arrangement that accommodates to the peculiarities of that commons $^{84}$. They can devise effective rules regulating its operation; impose graduated sanctions against 'free-riders'; and build systems of communication and coordination between users, which are aimed to promote trust and reciprocity of action amongst the community in order to equitably and sustainably manage a scarce commons for the mutual interests of all ${ }^{85}$.

Ostrom concedes, however, that a set of specific rules explaining why some CPRs are robust and others fragile could not coherently be developed. She states: 'Although the particular rules that are used within these various settings cannot provide the basis for an explanation of the institutional robustness and sustainability across these CPRs, part of the explanation that I offer is based on the fact that the particular rules differ. The differences in the particular rules take into account specific attributes of the related physical systems, cultural views of the world, and economic and political relationships that exist in the setting. Without different rules, appropriators could not take advantage of the positive features of a local CPR or avoid

\footnotetext{
${ }^{81}$ Ostrom, E. Doing Institutional Analysis: Digging Deeper Than Markets and Hierarchies. In: Menard and M. M. Shirley (eds.). 2005. Handbook of New Institutional Economics. Chapter 30, pp. 819 - 848 at p. 827. Springer: The Netherlands.

${ }^{82}$ Doing Institutional Analysis: Digging Deeper Than Markets and Hierarchies. Ibid at p. 841; and Basurto, X. and E. Ostrom. The Core Challenges of Moving Beyond Garrett Hardin. Journal of Natural Research Policy Research. 2009, Vol. 1(3), pp. $255-259$ at p. 256.

${ }^{83}$ Basurto and Ostrom. Ibid, p. 255.

${ }^{84} \mathrm{Ibid}$; Ostrom, E. The Rudiments of a Theory of the Origins, Survival, and Performance of CommonProperty Institutions. In: Bromley, D.W. (ed). 1992. Making the Commons: Theory, Practice and Policy. Institution for Contemporary Studies: San Francisco. Chapter 3, pp. 41 - 59; and Bollier, D. Elinor Ostrom and the Digital Commons. Forbes.com October 13, 2009. Available from: http://www.forbes.com/2009/10/13/open-source-net-neutrality-elinor-ostrom-nobel-opinionscontributors-david-bollier.html. Date Accessed: 13/10/2009.

${ }^{85}$ Bollier. Ibid.
} 
potential pitfalls that might be encountered in one setting but not others, ${ }^{86}$. Ostrom is, accordingly, of the opinion that given these peculiarities characters unique to individual natural resource systems, it would be mistaken to expect the discovery of a single best formula or a set of optimal mechanisms that can apply universally to commons situations and foster an effective governance and management institutional arrangement ${ }^{87}$. Instead of details of specific rules, Ostrom postulates that there are seven "design principles", including an eighth for larger and complex resources systems, which are generally present in most of the long-enduring CPR institutions studied. Here, "design principle" is to be taken to mean as "... an essential element or condition that helps to account for the success of these institutions in sustaining the CPRs and gaining the compliance of generation after generation of participants to the rules-in-use ${ }^{, 88}$. The design principles of robust CPR institutions Ostrom identified are listed as follows:

1. Clearly defined boundaries. There are rules laid down defining the boundaries of the CPR itself, and who can access and have rights to appropriate the resource units from the CPR.

2. Congruence between appropriation and provision rules and local conditions. Appropriation rules restricting time, place, technology, and, or, quantity of resource units are related to local conditions and to provision rules requiring labour, materials, and, or, money.

3. Collective-choice arrangements. Most actors affected by operational rules can participate in modifying operational rules.

4. Monitoring to ensure rule-compliance. Monitors, who actively audit CPR conditions and appropriators' behaviour, are accountable to the appropriators or are the appropriators.

5. Graduated sanctions for non-compliance. Users who violate operational rules are likely to be assessed graduated sanctions (depending on the seriousness and context of the offence) by other participants, by officials accountable to these participants, or by both.

6. Conflict-resolution mechanisms. Appropriators and their officials have rapid access to low-cost local arenas to resolve conflicts among appropriators or between appropriators and officials.

7. Minimal recognition of rights to organise. The rights of resource actors to devise their own institutions are not challenged by external governmental authorities.

\footnotetext{
${ }^{86}$ Governing the Commons: The Evolution of Institutions for Collective Action. Supra, note 3 at p. 89.

${ }^{87}$ McGinnis, M. and E. Ostrom. Will Lessons from Small-Scale Social Dilemmas Scale Up? In: Biel,

A., Eek. D., Garling, T., and M. Gustafson (eds). 2008. New Issues and Paradigms in Research on Social Dilemmas. Chapter 12, pp. $189-211$ at p. 193. Springer.

${ }^{88}$ Governing the Commons: The Evolution of Institutions for Collective Action. Supra, note 3 at p. 90.
} 
8. Nested enterprises for larger, complex resource systems. Appropriation, provision, monitoring, enforcement, conflict resolution, and governance activities are organised in multiple layers of nested enterprises.

The publication of Ostrom's 'Governing the Commons: The Evolution of Institutions for Collective Action' was a welcomed departure from the conventional wisdom of the 'Tragedy of the Commons' postulated by Hardin and his disciples. Based on the literature before and after Ostrom's publication, a reader of commonproperty management may reasonably conclude that the success of community-based governance is contingent upon the essential condition that resources users are free from intervention by external agents. Ostrom's studies however show that this conclusion is not wholly accurate. Although there are certain circumstances where it is possible for local communities who are users of small-scale resources to successfully manage that system providing they have autonomy to craft their own institutions and rules, the absence or lack of intervention from external authorities might not necessarily lead to durable communal arrangements ${ }^{89}$. The peculiar characteristics of the resource system, the rule-in-use and the attributes of the community are important factors which have a role in the design and implementation of the governance regime ${ }^{90}$. An interaction between local users and official authorities and other external agents in decision-making outcomes might optimally lead to the effective control and regulation of larger and complex resources. Such polycentric approach to governance has its strengths, and should not be immediately discounted as a viable institutional design ${ }^{91}$. Policy-makers are hereby reminded that, as the "design principles" suggest, the requirements for the institutional arrangement must change according to the diversity of individual CPRs and to the responses to ecological structures and cultural norms.

Ostrom's 'Governing the Commons' was a catalyst for the development of the theory of self-governance and self-organisation, and in turn an improved understanding to the problems of collective action in CPR settings. Since 1990, the methodological scope on the study of shared natural resource systems has broadened. Later scholars are harnessing the utility of interdisciplinary research by attempting cross-fertilisation of the conventional theories of collective action with other disciplines. It is hoped that such interaction with the disciplines would yield fresh insights on the role of property-rights systems to solve the problem of the tragedy of the commons in CPR arrangements, and the effects of alternative institutional regimes as an effort to incentivise resource users to make desirable outcomes which promotes

\footnotetext{
${ }^{89}$ Berge, E and F. van Laerhoven. Editorial: Governing the Commons for two decades: a complex story. International Journal of the Commons. 2011, Vol. 5(2), pp. 160 - 187 at p. 162.

${ }^{90}$ Doing Institutional Analysis: Digging Deeper Than Markets and Hierarchies. Supra, note 80.

${ }^{91}$ For example, Ostrom in later works argues that such a polycentric approach could efficiently deal the global problem of climate change. Commenting on the strengths of such regime, she states: 'The advantage of a polycentric approach is that it encourages experimental efforts at multiple levels, as well as the development of methods for assessing the benefits and costs of particular strategies adopted in one type of ecosystem and comparing these with results obtained in other ecosystems. A strong commitment to finding ways of reducing individual emissions is an important element for coping with climate change. Building such a commitment, and the trust that others are also taking responsibility, can be more effectively undertaken in small- to medium-scale governance units that are linked through information networks and monitoring at all levels'.
}

See: A Polycentric Approach for Coping with Climate Change. Supra, note 61 at p. 39. 
the long-term sustainability of the CPR and away from undesirable outcomes like opportunistic behaviour ${ }^{92}$. Accordingly, commentators studying commons resource management are now bring theoretical hypotheses into the biological world in order to validity or even displace their own theories. Berge and van Laerhoven, for example, observe these literary developments, and write: 'Standard case studies of land held common based on field observations and archival studies are now complemented by quasi-experimental methods and meta-analysis of core characteristics. The essence of the problem of the commons had been taken into laboratories where experiments with students playing commons dilemma games have provided new insights. Later, insights from laboratory studies were taken to field settings where real commoners by and large confirmed the general observations, but also documented larger diversity in responses than found among university students, 93 .

Furthermore, the types of CPRs studied have expanded and goes beyond the agricultural setting. A survey of the literature before 1990 shows that scholars concentrated on small-scale shared resources at the local and regional levels for the governance of such systems as irrigation reservoirs, groundwater basins, pastures and forests. Since Ostrom's Governing the Commons, the literature has moved its focus away from small-scale systems to common-pool resources at the global level. Here, institutional analysts are examining larger and complex resources at the international level, such as terrestrial resources like the oceans and the atmosphere as well as extraterrestrial systems like the radio orbital spectrum in outer space, and questioning how these global commons can be sustainably governed and managed ${ }^{94}$. There appears, however, to be two camps among commons writers who are divided in thought on the relevance and viability of applying the design principles to larger scale resources systems than those CPRs studied which Ostrom derived her insights, that is to say land-based CPRs such as inshore fisheries, grazing areas and communal forests, where the resource system itself was located within one country and the number of individuals affected by that commons varied from 50 to 15,000 person who were heavily dependent on the CPR for economic gains ${ }^{95}$. The first camp of political scientists hold the opinion that the design principles are inductive generalisations from a set of real-world cases where the CPRs studied shared the set of characteristics described, arguing that Ostrom's propositions are incomplete; additional criteria for the sustainable governance of small-scale must be taken into account ${ }^{96}$. Some emphasise on the importance of social mechanisms to CPR regimes rather than the proposed boundary and payoff rules, suggesting that an explanation why some communities in Ostrom's research were successful manage shared resources themselves and while other not was the critical factor that each individual belonged to a 'community of mutually vulnerable actors" ${ }^{97}$. As Harkes writes, "[t]he design principles of Ostrom and other scientists who have pursued this line of thinking thus are an interesting point of exit, but only partly explain the success of management

\footnotetext{
${ }^{92}$ Land use, environmental change, and sustainable development: the role of institutional diagnostics. Supra, note 36 at p. 67.

${ }^{93}$ Berges and van Laerhoven. Supra, note 87 at p. 162.

${ }^{94}$ Ibid, p. 162.

${ }^{95}$ Governing the Commons: The Evolution of Institutions for Collective Action. Supra, note 3 at p. 26.

${ }^{96}$ McGinnis and Ostrom. Supra, note 87 at p. 197.

${ }^{97}$ Singleton and Taylor cited by Cox et al. See: Cox, M., G. Arnold., and S.V. Tomas. A Review of the Deisng Principles for Community-based Natural Resource Management. Ecology and Society. Vol. 15(4). Available from: http://www.ecologyandsociety.org/vol15/iss4/art38/. Date Accessed: 14/02/2013. See, also: Cole, D.H. 2004. Pollution and Property: Comparing Ownership Institutions for Environmental Property. Cambridge University Press: Cambridge at p. 123.
} 
institutions. Most of the conditions mentioned are merely characteristics of the community or institution, such as scale, village size, homogeneity, or the ability to exclude outsiders, and even though these factors undoubtedly contribute to their functionality, from our study it has become clear that the real 'glue' that keeps an institution alive over time are the social mechanisms, i.e., trust, legitimacy, and transparency" "98. This camp also conveys their doubts on the applicability of the principles to global scale resources where the environmental characteristics differ to those local-scale systems ${ }^{99}$. Berkes, for examples, queries: 'Globalization has a major impact on local-level resource management through such mechanisms as the creation of international markets. Can a theory of the commons, based on local-level cases, be scaled up to deal with the complexity of communities and social-political networks? ${ }^{100}$. Young is one analyst who argues that such scale-up is unlikely, He recommends that, for sustainable results, an institutional diagnostic analytical approach that seeks to match institutional arrangements to the specific biophysical and socio-economic conditions of the resource system concerned should be adopted than an ideology approach that advocate the application of one system of propertyrights to all situations which includes Ostrom's generalised principles ${ }^{101}$.

The second camp of policy analysts, on the other hand, are confident that Ostrom's design principles are a starting pointing for the crafting of successful institutional regimes for larger CPRs. They argue that, along with the lessons learnt from empirical research concerning the management regimes at the local scale, those principles can apply across to commons resources at global scale. However, such scale-up is not automatic. By comparing the different types of commons at the local and global scale, and considering such issues as the geographic scale, the number of resource users, distribution of interests and powers and the cultural and institutional homogeneity, it becomes it is apparent that small-scale commons at the local and regional level, on the one hand, and large-scale at the global level, on the other hand, are essentially different things ${ }^{102}$. To that end, as McGuinns and Ostrom emphasise, '...due care must be taken in the process of extrapolating from one institutional context to another' ${ }^{103}$ in order to generate long-enduring and successful arrangements. In other words, the modelling of the governance system must be fashioned according to the peculiar characteristics of that specific commons resource, and has the capacity to evolve over time as information about or characteristics of the resource, including the environment itself, change. This concept is referred to as 'adaptive governance', which is defined as '.. . a set of rules crafted to fit one set of socioecological conditions can erode as social, economic, and technological developments increase the potential for human damage to the ecosystems and even to the biosphere itself. Furthermore, humans devise ways of evading governance rules. Thus, successful commons governance requires that rules evolve ${ }^{104}$. The importance of "adaptive governance" in the design of the sustainable management regimes for global resources can be demonstrated by such scholars as Stern. In his works, Stern departs

\footnotetext{
${ }^{98}$ Harkes cited by Cox et al. Supra, note 97.

${ }^{99}$ Cox et al. Supra, note; and McGinnis and Ostrom. Supra, note 87 at p. 197

${ }^{100}$ Berkes cited by Cox et al. Ibid.

${ }^{101}$ Land use, environmental change, and sustainable development: the role of institutional diagnostics. Surpra, note 35; and Young, O. R. 2002. The institutional dimensions of environmental change: fit, interplay, and scale. MIT Press: Massachusetts.

${ }^{102}$ Berges and van Laerhoven. Supra, note 89 at p. 169.

${ }^{103}$ McGinnis and Ostrom. Supra, note 87 at p. 193.

${ }^{104}$ Dietz, T., E. Ostrom., and Stern, P. The Struggle to Govern the Commons. Science. 2003, Vol. 302(5652), pp. 1907 - 1912 at pp. 1907 - 1908.
} 
from the opinion held by commentators belonging to the first camp that there are missing tools in the policy-makers' analytical toolkit for the study of complex CPRs at the international level ${ }^{105}$. He critically scrutinises Ostrom's eight design principles, examining their respective applicability to the understanding of governance for global commons. Stern's analysis indicates that the management of international resources raise special challenges which are not met by the literature on local resource regimes, and thus the principles utilised for governing these commons may not be identical to those applied to small-scale CPRs. Nonetheless, Sterns argues that Ostrom's original design principles are useful, and can be resourceful for the study of international commons providing certain modifications and additional principles are adopted to address those special challenges. ${ }^{106}$ For example, Principle 3, referred to the "collective-choice arrangement" above, poses practical implications. This principle that allows most resource users to participate in the development of the operational rules that regulates access and use of the resource may indeed be relevant to the global commons, but is challenged by the size of the appropriators entitled to make such decision outcomes. In the context of global commons, Principle 3 can be interpreted widely in that the sense that the class of resource users authorised to craft the operational rules can potentially be so large as to include entire human

population ${ }^{107}$. To overcome these implications, Stern suggests that Principle 3 must be "unpacked" and reinterpreted to limit the scope of eligible users entitled to become a member of institutional arrangement and participate in decision-making outcomes. He writes: 'Allowing most users to participate in developing the rules is a huge challenge if one treats the entire human population as the users. The fact that the benefits and costs of degradation fall to largely different groups virtually ensures conflict in any particular governance context. The design principle needs to be unpacked: Which groups of users should be involved in making which rules? And if the major degraders have incentives to externalize much of the cost, what would get them to design rules that would protect the commons? There is also the issue of how "most users" can participate meaningfully when there are so many, and when the system is so complex as to challenge the understanding of even the most expert scientists. Because of these challenges, the design principle needs to be rephrased for global resource commons: Ensure meaningful participation of the range of interested and affected parties in developing rules (emphasis original) ${ }^{, 08}$.

\subsection{Part Three - Ostrom In Space}

Part One critically scrutinised Hardin's 'Tragedy of the Commons' and Ostrom's 'design principles'. It examined the strengths and weaknesses of each author's institutional solutions to control resource users' from acting and behaving opportunistically in their utility of the commons and appropriation of its limited resource units in order to avert the environmental degradation and possible ruin of scale-scale natural resources. Part One also considered why many commentators since 1990 have departed from the conventional wisdom under the Hardinian model to find Ostrom's institutional arrangement of "community-based governance" as a

\footnotetext{
${ }^{105}$ Stern, P.C. Design Principles for global commons: Natural Resources and Emerging technologies. International Journal of Commons. Vol. 5(2), August 2011, pp. 213 - 232.

${ }^{106}$ Ibid, pp. $219-223$.

${ }^{107}$ Ibid, p. 221.

${ }^{108}$ Ibid.
} 
compelling alternative to Hardin's prescriptions for robust and sustainable CPR regime.

Part Two applies Ostrom's design principles to the space debris problem, determining the appropriateness and feasibility of adopting Ostrom's framework provide a governance regime for outer space. It acknowledges that scaling-up Ostrom's original principles, which were produced through empirical studies of small-scale, terrestrial CPRs, to a larger, extraterrestrial commons poses challenges. Part Two takes each principle in turn, assessing its relevant to the Space Commons and identifying any challenges which would occur in the scaling-up process. If the principle has relevancy but challenges exist, it examines if the existing space governance regime can met those issues. If it cannot or does but produces suboptimal outcomes, Part Two suggests what must be done to satisfy that principle. By following this analytical approach, the end-product would be an alternative institutional arrangement for outer space which is based on Ostrom's "communitybased governance". What must be researched elsewhere, however, is the institutional legitimacy of a governance regime that consists of both state and non-state actors who are responsible for overseeing access and regulating use of space, and managing collective action problems such as orbital debris.

\subsubsection{Principle 1: Clearly defined boundaries}

Under Principle 1, there are rules which define the boundaries of the CPR itself, and identify individuals who are authorised to access and have rights to appropriate the resource units from the CPR. Principle 1 is an essential first step in organising collection action, and its importance is stressed by Ostrom who writes: 'So long as the boundaries of the resource and/or the specification of individuals who can use the resource remains uncertain, no one knows what is being managed or for whom. Without defining the boundaries of the CPR and closing it to "outsiders", local appropriators face the risk that any benefits they produce by their efforts will be reaped by others who have not contributed to those efforts. At the least, those who invested in the CPR may not receive as high a return as they expected. At the worst, the actions of others could destroy the resource itself. Thus, for any appropriators to have a minimal interest in coordinating patters of appropriation and provision, some set of appropriators must be able to exclude others from access and appropriation rights. If there are substantial numbers of potential appropriators and the demand for the resource units is high, the destructive potential should all be allowed to freely withdraw units from the CPR could push the discount rate used by appropriators toward $100 \%$. The higher the discount rate, the closer the situation is to that of a oneshot dilemma in which the dominate strategy of all participants is overuse the $\mathrm{CPR}^{109}$.

Space is and apart of complex, interconnected resource system. A telecommunications operator, for example, must enter and use two different commonpool resources in order to carry out its planned space activity. By launching the satellite from the surface of the Earth, that launcher would have had entered and used the atmosphere, or the Airspace Commons, to enter the final frontier. Having exited the point where airspace ends and space begins, the satellite would continue travelling in the near-Earth orbits; that is Low Earth Orbit (LEO) until it reached its allocated orbital slot in the Geostationary Earth Orbit (GEO), which is argued as forming the

${ }^{109}$ Governing the Commons: The Evolution of Institutions for Collective Action. Supra, note 3 at p. 91. 
Space Commons. From this hypothetical example, it becomes apparent that physical boundaries between the Airspace Commons and the Space Commons, hereby defining the point where airspace ends and space begins and excluding unauthorised actors from accessing the resources and free-riding, is not scientifically possible as the environmental structures of the two resources systems are significantly different. By the same token, erecting physical barriers which "ring-fence" near-Earth orbits from others is not viable.

Notwithstanding the scientific impossibility of using physical mechanisms, the definitions and delimitations of airspace and outer space has proven a challenge to the legal community since the successful launch of Sputnik 1 in 1957 because of the concepts of sovereignty and jurisdiction. This matter arose following the enactments of the Paris Convention in 1919 and the Chicago Convention in 1994 that declared under international air law nation-states have complete and exclusive sovereignty over the airspace above its territory ${ }^{110}$, but failed to define what amounts to airspace and where it ends. It was long recognised that the lack of a definition or delimitation of outer space created legal uncertainty concerning the applicability of space law and air law, and that matters concerning state sovereignty and the boundary between airspace and outer space needed to be clarified in order to reduce the possibility of disputes among states. However, before the creation of international space law, legal commentators were divided into two groups on how to address this uncertainty. One camp suggested that state sovereignty should extend into space, arguing that such extension was out of necessity during the Cold War and an appropriate response to foster peace between the U.S. and U.S.S.R by ensuring that their respective space agendas were unaffected by the lack of definition and boundary line between of airspace and outer space ${ }^{111}$. The second group, on the other hand, argued that the proposed extension of state sovereignty in space would be astronomically impossible given the planetary physical realties between the CPRs involved are so different. As Beresford explains, 'Let us first consider the view that national sovereignty extends into outer space without any limit whatever. A cone of sovereignty conceived as stretching into space from the center of the earth through the territorial boundaries of each nation would clash with the facts of astronomy. With the movement of the earth and other astronomical bodies, the concept of each nation's cone of sovereignty would change continually. Any given point in space would constantly pass from one cone of sovereignty to another. A rocket could not go from earth to the moon, for example, without crossing through the sovereign in space of many nations, ${ }^{112}$. Under this group, supporters were of the view that the extension of state territory to space was not workable in the real-world, and that the solution laid with international air law identifying the boundary where airspace ended ${ }^{113}$.

Neither the first nor second group was able to influence the drafters of the space treaties with their respective proposals, however. Article II of the Outer Space Treaty declares that 'Outer space, including the Moon and other celestial bodies, is not

\footnotetext{
${ }^{110}$ See, respectively, Article 1 of the Paris Convention and Article 1 of the Chicago Convention.

Paris Convention for the Regulation of Aerial Navigation, Oct. 13, 1919, 11 L.N.T.S. 173; and Convention on International Civil Aviation, Dec. 7, 1944; 61 Stat. 1180, 15 U.N.T.S. 295.

${ }^{111}$ Dodge, M.S. Sovereignty and the delimitation of airspace. A philosophical and historical survey supported by the resources of the Andrew G. Haley archive. Journal of Space Law. 2009. Vol. 35, pp. 5 -35 at p. 24 .

112 Beresford cited by Dodge. Ibid, p. 30.

${ }^{113}$ Dodge. Ibid, pp. $30-31$.
} 
subject to national appropriation by claim of sovereignty by means of use or occupation, or by any other means, ${ }^{114}$. Nor has a specific international agreement defining the boundary between airspace and outer space been adopted ${ }^{115}$. The definition and demarcation of outer space is therefore the oldest unresolved matters, and remains still on the agenda of Legal Subcommittee (LSC) of the COPUOS since $1966^{116}$.The Subcommittee has recently renewed its interest on this matter. It acknowledged that the emergence of new space technology, the intensification and diversification of space activities, including the increasing commercial use of space, may have made it necessary for the Subcommittee to reconsider the question in order ensure legal certainty among disputing states as to when and where the air or space regime applies ${ }^{117}$. It, however, was the General Assembly that decided that the LSC should establish a Working Group, on a priority basis, "matters relating to the definition and delimitation of outer space and to the character and utilization of the geostationary orbit, including the elaboration of general principles to govern the rational and equitable use of the geostationary orbit, a limited natural resource"118. The Working Group produced a questionnaire on the possible legal issues with regards to aerospace objects. The LSC finalised and agreed to the text, stating that the purpose of the questionnaire was to seek the preliminary views of member states of the United Nations on various issues relating to aerospace objects, and that the replies to the questionnaire could provide a basis for the Subcommittee to decide how it might continue its consideration of the agenda items ${ }^{119}$. Nations-states were invited to convey their views in favour or against establishing a definition and delimitation of outer space. From the compilation of replies received to the questionnaire, there is no agreement however among countries on the approach to be taken on this matter ${ }^{120}$. On the one hand, there are some states that viewed a definition and boundary of outer space as a legal basis through which to regulate their national territories and to resolve practical issues arising from collisions that could occur between aerospace objects and aircraft $^{121}$, The remaining member states, on the other hand, viewed that it was not necessary to develop a definition and delimitation of outer space when the absence of such a definition had not resulted in any legal or practical problems. These countries believed that the differing legal regimes applicable in respect of airspace and outer space did well in their respective domains, and that the lack of a definition and

\footnotetext{
${ }^{114}$ Article II of the Outer Space Treaty. Treaty on Principles Governing the Activities of States in the Exploration and Use of Outer Space, including the Moon and Other Celestial Bodies. United Nations General Assembly Resolution 2222(XXI) annex. $1499^{\text {th }}$ plenary meeting. Adopted on December 19, 1966 and entered into force on October 10, 1967. International Legal Materials. 1967, Vol. 6, pp. 386 $-390$.

${ }^{115}$ Lyall, F. and P.B. Larsen. 2009. Space Law: A Treaties. Ashgate Publishing Limited: Surrey at p. 153.

${ }^{116}$ Official Records of the General Assembly, Twenty-first Session, Summary Records of Meetings, First Committee, 1492nd meeting, para. 21 (A/C.1/SR.1492); Verbatim Records of Meetings, Plenary, 1499th meeting, paras. 148-150 A/PV.1499); and General Assembly resolution 2222 (XXI), para. 4 (b). Also, see: United Nations General Assembly. Historical summary on the consideration of the question on the definition and delimitation of outer space: Report of the Secretariat. Committee on the Peaceful Uses of Outer Space Legal Subcommittee. Forty-first session, Vienna, 2 - 12 April 2002.

A/AC.105/769.

${ }^{117}$ A/AC.105/763 and Corr.1, para. 54, and annex I, para. 5.

${ }^{118}$ General Assembly Resolution 38/80 of 15 December 1983

${ }^{119}$ See A/AC.105/607 and Corr.1, paras. 38 and 39 and annex I, paras. 28-30; and Official Records of the General Assembly, Fiftieth session, Supplement No. 20 (A/50/20), para. 117.

${ }^{120}$ Responses received from member states to the questionnaire have been issued and under document A/AC.105/635 and its addenda.

${ }^{121}$ A/AC.105/763 and Corr.1, para. 54, and annex I, para.5.
} 
delimitation of outer space had not impeded development of activities in either sphere $^{122}$. In addition to the diverging views expressed at the international arena, there are asymmetrical legal responses operating in parallel at the national arena. A minority of member states have defined and delimit outer space. South Africa, for example, under the South African Space Affairs Act of 1993 defines "outer space" as meaning "the space above the surface of the Earth from a height at which it is practice to operate an object in orbit around the Earth" ${ }^{123}$. Australia appears to recognise that outer space begins at the altitude of 100km under it Space Activities Act of 1998 which governs all launches above that altitude ${ }^{124}$. Less-developed countries which lack space-capabilities such as Madagascar do not have any space law or regulations, and refer to relevant provision under international law ${ }^{125}$.

Although consensus among member states could not be facilitated, the lengthy debates at COPUOS have led to attempts to conceptualise and delimit the airspace and outer space which has resulted to the development of two schools of thought. The first is "spatialist approach". Here, proponents of this school wish to deal with the boundary between airspace and outer space objectively by establishing a physical demarcation to separate the two domains on the basis of altitude. Australia is one such supported of this school in light of its enactment of the 1998 Space Activities Act. The dissolved Soviet Union viewed this approach favourably, proposing to COPUOS in 1979 that '.. the boundary between outer space and air space should be established by agreement among States at an altitude not exceeding $110 \mathrm{~km}$ above sea level and should be legally confirmed by the conclusion of an international legal instrument of a binding character; and, secondly, that the instrument should also specify that a space object of any State should retain the right of innocent (peaceful) flight over the territory of other States at altitudes lower than the agreed boundary for the purpose of reaching orbit or returning to Earth ${ }^{126}$. A similar view was expressed by the Russian Federation in its reply to the questionnaire of LSC's Working Group, and is reflected in its national space law framework ${ }^{127}$. The second school of thought is the 'functionalist approach', arguing that there should be no physical delimitation of the two domains on the basis of altitude. Rather, the function of the vehicle used in the activity should determine which regime applies. Accordingly, a vehicle that operates in the air only, air law should govern. By the same token, if the vehicle is built to be launched into space, the outer space regime should govern ${ }^{128}$. Both schools of thought nonetheless have their own strengths and weaknesses ${ }^{129}$, and whether such theories and even the question on the boundary between the airspace and outer space remains as a "live" issue should be reconsidered in light the emergence of new space technology. This is because there is a next generation of space vehicles under

\footnotetext{
${ }^{122} \mathrm{Ibid}$, para. 57, and annex I, para.6.

${ }^{123}$ A/AC.105/635/Add.7 of 13 January 2003. Also, see: Responses received from member states to the questionnaire have been issued and under document A/AC.105/635 and its addenda.

${ }^{124}$ Jakhu, R. Legal issues relating to the global public interest in Outer Space. Journal of Space Law. 2006, Vol. 32 pp. $31-110$ at pp. $193-194$.

${ }^{125}$ A/AC.105/635/Add.10 of 21 January 2004. Also, seeResponses received from member states to the questionnaire have been issued and under document A/AC.105/635 and its addenda.

${ }^{126}$ A/AC.105/C.2/L.139.

127 A/AC.105/635/Add.1 of 15 March 1996. See, also: Russian Federation Act on Space Activity adopted in 1993,

${ }^{128}$ Dodge. Supra, note 111 at p. 26.

${ }^{129}$ See: Lyall and Larsen. Supra, note 115 at pp.165 - 170.
} 
development by non-governmental entities in such countries as the U.S ${ }^{130}$. These vehicles called Reusable Launch Vehicles (RLVs) would have hybrid technological capabilities, allowing both conventional flights suitable for civilian travel at 40 kilometres and sub-orbital flights at approximately 120 kilometres above the surface of the Earth ${ }^{131}$. There are many who are of the opinion that the emergence of a definition delimiting airspace and outer space would serve little utility in the realworld and may indeed create additional legal challenges at both the international and national arenas ${ }^{132}$. Lyall and Larsen, for example, write: 'The long and the short of the matter seems to be that, military questions apart, there has as yet been no objective cogent requirement formally and precisely to differentiate air-space and outer space. The space-capable states have seen no reason potentially to restrict their abilities to use space by coming to agreement as to its lower boundary. The non-space-faring states are in no position to exercise any pressure in the matter' ${ }^{133}$.

Whereas the classical literature focused on the delimitation of airspace and outer space, another challenge has reached fruition recently within both the air and space (or aerospace) communities. This concerns the intermediate domain between airspace and outer space which scientists call "near-space" and is defined as an atmospheric region from about $20 \mathrm{~km}$ to $100 \mathrm{~km}$ above the surface of the Earth $^{134}$.The environmental characteristics, and hence the utility of this domain, are different to that of the airspace and outer space. The atmosphere in near-space is too thin to support flying for airplanes and yet too thick to sustain orbit for satellites ${ }^{135}$. Nonetheless, the development of a new type of vehicles known Near Space Vehicles (NSVs) has made it possible to carry out activities in this domain. As with the boundary debate between airspace and outer space, there is legal uncertainty as to definition and delimitation of near-space. Another significant challenge is determining how to govern and regulate the Near-Space Commons whether through air law, space law or even a new regime. It is submitted that neither air law nor space law are appropriate given the environmental structure between the commons are different and unique to their respective commons. A regime tailored to near-space can be created, but there is a danger of overregulation within the aerospace community which can add to legal ambiguities and, in turn, stifle market development. In light of recent technological developments with vehicles possessing hybrid capabilities, there is the option of abolishing air law and space law and replacing with a single framework, called here as "aerospace law", that regulates and oversees activities in all three domains: airspace; near-space and outer space. However, the appropriateness and feasibility of designing and implementing such regime would require further research.

\footnotetext{
${ }^{130}$ Virgin Galactic is one such commercial company with the aim of providing affordable human space flights to the paying public. See: Leonard, T. New Mexico town to host world's first spaceport. The Telegraph. December 31, 2009. Available from:

http://www.telegraph.co.uk/science/space/6917074/New-Mexico-town-to-host-worlds-firstspaceport.html. Date Accessed: 31/12/2009.

${ }^{131}$ Vogler. Supra, note 51 at p. 101; and Hughes, T.R. and Rosenberg. E. Space travel law (and politics): The evolution of the Commercial Space Launch Amendment of Act of 2004. Journal of Space Law. 2005, Vol. 31, pp. $1-80$ at pp. 6-11.

${ }^{132}$ Meek, P.A. The CPR approach to space sustainability: Commentaries on Weeden and Chow. Space Policy. Available from: http://dx.doi.org/10.1016/j.spacepol.2012.06.006. Date Accessed: 30/06/2012.

${ }^{133}$ Lyall and Larsen. Supra, note 115 at p. 162.

${ }^{134} \mathrm{Su}$, J. Near space as a sui generis zone: A tri-layer approach of delimitation. Space Policy. 2013, Vol. 29, pp. 90 - 92; and Wang, W.Q. 2011. Near Space Remoting Sensing: Potential and Challenges. Springer: London at pp. $1-2$.

${ }^{135}$ Ibid.
} 
Principle 1 also requires that there is certainty with the rules to as to who may and may not enter the commons, and specify what rights resources beneficiaries have in their appropriation of its resource units. Under the existing international legal framework for space, outer space has the legal status as an international or global commons. As Article II of the Outer Space Treaty provides, 'Outer space, including the Moon and other celestial bodies, is not subject to national appropriation by claims of sovereignty, by means of use or occupation, or by any other means'. In addition to saying that space not subject to claims of state sovereignty, this treaty also confirms that outer space is a resource system that has multiple users with multiple uses. Whereas accessibility and usage of Geostationary Earth Orbit (GEO) is strictly controlled and limited to members of the International Telecommunications Union (ITU) regime, the increasing affordability of building and launching a space object into outer space, including the geostationary orbit but not for telecommunications purposes, means that the final frontier can be entered by any entity whether governmental entities, commercial enterprises and even private individuals, providing that launching licence and other requirements under the national law of the launching state have been satisfied ${ }^{136}$. Such actors, owing to Article I(1) of the Outer Space Treaty, are vested with the rights to enjoy free access to these common resource systems and carry out space-related activities without discrimination and on the basis of equality ${ }^{137}$.

Outer space therefore suffers from the 'problem of excludability'; that is to say, the substantial difficulty, but not impossibility, of devising and implementing physical and institutional mechanisms to exclude individuals from the resource units of a commons without incurring high $\operatorname{costs}^{138}$. Save for military action during the launching stage of the space object, neither the space treaties nor international pressure can effectively exclude actors from accessing and using space for nonpeaceful purposes. Here, "non-peaceful purposes" is not limited in the military sense such as to the placement of weapons of mass destruction ${ }^{139}$, but includes operations which could cause harmful interference to the space environment ${ }^{140}$. For example, the space community was unable to prevent China from entering space in 2007 when it carried out an anti-ballistic missile test (ASAT) by intentionally destroying its own derelict satellite with a missile, contrary to a de facto rule against such missions that was established and observed for more than 25 years ${ }^{141}$. Likewise, international pressure to abandon what was perceived by many as being a long-range ballistic missile test did not to deter North Korea from successfully launching its rocket which was claimed to be carrying a satellite in December $2012^{142}$.

\footnotetext{
${ }^{136}$ Buck, S.J. The Global Commons: An Introduction. Island Press: Washington, D.C. at p. 138.

${ }^{137}$ Article I(2) of the Outer Space Treaty states: 'Outer Space, including the Moon and celestial bodies, shall be free for exploration and use by all States without discrimination of any kind, on a basis of equality and in accordance with international law, and there shall be free access to all areas of celestial bodies'. See: Outer Space Treaty. Supra, note 114.

${ }^{138}$ Ostrom, E., J. Burger., C.B. Field., R.B. Norgaad., and Policansky, D. Revisiting the Commons:

Local Lessons, Global Challenges. Science. 1999, Vol. 284, pp. $278-282$ at pp. $278-279$.

${ }^{138}$ Ostrom et al. Ibid, p. 278.

${ }^{139}$ Article IV of the Outer Space Treaty. Supra, note 114.

${ }^{140}$ Article IX of the Outer Space Treaty. Supra, note 114.

${ }^{141}$ Hitchens, T. The United Nations and its efforts to develop treaties, conventions or guidelines to address key space issues including the de-weaponization of space and orbital debris. In: Petlton, J.N. and R.S. Jakhu. 2010. Space Safety Regulations and Standards. Butterworth-Heinemann: Boston. Chapter 21, pp. $267-274$ at p. 269.

${ }^{142}$ Mcurry, J. and T. Brangian. North Korea rocket launch succeeds in face of criticism. The Guardian. December 12, 2012. Available from: http://www.guardian.co.uk/world/2012/dec/12/north-korea-
} 
According to the commons literature, the absence of well-defined access rights limiting persons entering the resource system can result to 'free-riding' and may occur in two ways. The first involves the overuse of the resource system without due regard to the negative consequences on other users ${ }^{143}$. The second form is the lack of contribution towards the management and improvement of the CPR itself ${ }^{144}$. After more than half a century of human space activity, the space community have witnessed that there are free-riders who are exploiting the rights vested under Article I(1) in their use and exploration of outer space. There are accounts of opportunistic members of the space community seeking short-term gain for profit, technological innovation or otherwise, knowingly undertaking unsafe and risky space operations with little or no regard for the externalities produced to other space users and the space environment itself. In the continued absence of exclusion mechanisms, such patterns of irresponsible behaviour would be recurring and thus result in suboptimal outcomes than would have otherwise been had actors cooperated by reciprocating conducts of behaviour deemed acceptable by all or most of the members of the community $^{145}$.

Ostrom's Design Principle 1 is, therefore, not wholly relevant and applicable to global CPRs, and must be adjusted to the peculiar attributes of space ${ }^{146}$. Unlike terrestrial-based commons, it is not scientifically possible to set physical boundaries for an extraterrestrial commons. International space law does not define or delimit outer space. Nor does the space treaties offer a resolution and thus certainty to the oldest matter relating to the boundaries between airspace and outer space, and is further challenged with the advent of a third CPR, Near-Space. Notwithstanding the lack of delimitation of the two main domains - airspace and outer space - no significant legal challenges have arisen as of today. Accordingly, it is suggested that Ostrom's original principle should be modified in the context of the space so that clearly boundaries between the airspace and outer space are not essential until such disputes arise in the legal arena.

Efforts must however be concentrated on prescribing clear rules as to who may or not enter the resource, and what rights are vested to resource beneficiaries in their utility of the commons and the appropriation of its limited resource units. Under international space law, outer space is not subject to claims of state sovereignty, and is an open-access resource in the sense that any entity with the necessary financial and technical competencies can gain free entry and appropriate the limited natural resources without discrimination and the basis of equality. It is argued that the space community's inadequacy to regulate access by excluding opportunistic actors and oversee operational use of space by restraining excessive appropriation of the limited space resources, and in turn assuring the safety and sustainability of its environment, is a direct outcome from the space treaties that fails to impose a mandatory international obligation on state parties to register space objects to the United Nations, or more accurately the United Nations Office of Outer Space Affairs (UNOOSA) which is responsible for maintaining the UN Registry of Space Objects, prior to its

launches-rocket.Date Accessed:12/12/2012. and Hertzfeld, H.R. and S. Li. Registration of the 12 December satellite launch by North Korea: should UNOOSA have accepted it? Space Policy. 2012, Vol. 29, pp. 93 - 94.

${ }^{143}$ Ostrom et al. . Supra, note 138 at p. 278.

${ }^{144}$ Ostrom, E. The Rudiment of Theory of the Origins, Survival, and Performance of Common-Property Institutions. In: Bromley, D.W. (ed). 1992. Making the Commons Work: Theory, Practice, and Policy. Institute for Contemporary Studies: San Francisco, pp. 293 - 315 at p. 296.

145 Governing the Commons: The Evolution of Institutions for Collective Action. Supra, note 3 p. 38.

${ }^{146}$ Stern. Supra, note 104 at p. 219. 
launch. Article XI of the Outer Space Treaty purports that state parties to the treaty agree to inform the Secretary-General of the United Nations as well as the public and the international scientific community, to the greater extent feasible and practicable, of the nature, conduct, locations, and results of such activities (emphasis added). On receiving this information, the Secretary-General of the United Nations should be prepared to disseminate it immediately and effectively. Article IV of the Registration Convention is written in similar terms but specifies that the information provided by state parties should transmit to UNOOSA. The provision also prescribes that this responsibility is a continuous obligation in the sense that they are to notify the Secretary-General, to the greatest extent feasible and as soon as practicable (emphasis added), if the information previously furnished have changed and includes information on space objects which are no longer in orbit ${ }^{147}$. The registration requirements are a form of transparency and confidence-building measures (TCBMs) for space activities in order foster trust and confidence among and between members of the space community and their respective space agendas, and minimise the risks of misunderstandings and misperceptions ${ }^{148}$. However, such purpose is undermined in light of above event involving China and North Korea which underscored the opaque nature of the country's respective space agendas and heightened concerns over the safety of the orbits from possible military use. Furthermore, the rate of compliance with the registration requirements has declined after more than 30 years of practice ${ }^{149}$. Not every space object launched into outer space is registered on the UN Registry of Space Objects. With reference to the event described above, North Korea has ratified both the Outer Space Treaty and Registration Convention and therefore is a state party to those treaties. Consistent with the obligation under Article IV of the

\footnotetext{
${ }^{147}$ Article IV(1) of the Registration Convention reads:
}

'1. Each State of registry shall furnish to the Secretary-General of the United Nations, as soon as practicable, the following information concerning each space object carried on its registry:

(a) Name of launching State or States;

(b) An appropriate designator of the space object its registration number;

(c) Date and territory or location of launch;

(d) Basic orbital parameters, including:

(i) Nodal period;

(ii) Inclination;

(iii) Apogee

(iv) Perigee;

(e) General function of the space object.

2. Each state of registry may, from time to time, provide the secretary-General of the United Nations with additional information concerning a space object carried on its registry.

3. Each state of registry hall notify the Secretary-General of the United Nations, to the greatest extent feasible and as soon as practicable, of space objects concerning which it has previously transmitted information, and which have been put no longer are in Earth in orbit.

See: Convention on Registration of Objects Launched into Outer Space, adopted by the General Assembly in its resolution 3235 (XXIX), opened for signature on 14 January 1975, entered into force on 15 September 1976.

\footnotetext{
${ }^{148}$ Hertzfeld and Li. Supra, note 142 at p. 94.

${ }^{149}$ Spencer Jr., R.L. 2008. Implementing International Standards for “continuing supervision”. LL.M Thesis submitted to Institute of Air and Space Law, Faculty of Law, McGill University at p. 41.
} 
Registration Convention, the country submitted to the UN Secretary-General after or, in the language of the treaty, "to the greatest extent feasible and as soon as practicable", launch of the satellite. Notwithstanding the military complications attached with the launch and its underlying purpose, UNOOSA failed to place the information it received from North Korea, contrary to its legal duty under Article III of the Registration Convention ${ }^{150}$. It is accordingly argued that the space treaties, allowing registration of the space after the launch of the outer space, is selfeliminating. It undermines the spirit of the Registration Convention to promote transparency and confidence within the space community by reducing the risks of misunderstandings and misperceptions about state actor's space policies and the underlying nature behind their existing and planned missions. As demonstrated with the event above concerning China and North Korea, the space community may only convey its criticisms post-launch of the space object.

From the commons literature, empirical findings shows that where resource appropriators have knowledge or can accurate anticipate the actions and behaviour of others, rule-infractions can be detected, allowing the community to adopt appropriate deterrence mechanisms to coerce rule-compliance, As information relating to actors' strategies can be predicted, it may encourage individualistic actors to forgo immediate economic returns from their excessive appropriation of the limited resource units in order to preserve the distant benefits for future members. In other words, selfish appropriators may reciprocate acceptable patterns of behaviour and conducts to avoid sanctioning and possible exclusion from the resource itself. The product is therefore a cooperative relationship based trust and confidence among members of the resource, which is essential for the optimal management and utility of the commons ${ }^{151}$. In light of these real-world findings, Ostrom's framework for an alternative space governance regime replaces the registration requirements under the Registration Convention with the 'Debris Environmental Damage Assessment' (DEDA) mechanism. In short, this would require the establishment of a new regulatory body. As opposed to a centralised regulator like an "International Space Authority" that is ran by nation-states for states, there would be an association incorporated and its membership takes into account for Ostrom's design principle 3. That is to say, the space appropriators most affected and interested by the operational rules would be members of the "Association of Space Appropriators" (ASA) and are vested with the decision-making powers to participate in the crafting of the operational rules. Accordingly, the composition of the Association would include both state and non-state actors. Under the DEDA, registration of the space object is mandatory for all space actors, and is a prelaunching requirement for the launch of the object and its operational use in space to be considered lawful. The particulars of information, which mirror Article IV of the Registration Convention, should be submitted to the Association and would be readily accessible to the public without charge. After its receipt, the ASA reviews the DEDA and makes a decision in respect of approving and publicly announcing that the planned space activity is safe, and notifies whether the space operator is authorised to carry out the endeavour lawfully or not. However, before such result is determined, the space sector has sufficient time to scrutinise the environmental impact assessment following its public dissemination. Here, the industry can submit 'reasonable' and 'legitimate' challenges directly to the ASA against the authorisation of the

\footnotetext{
${ }^{150}$ Hertzfeld and Li. Supra, note 142 at p. 94.

${ }^{151}$ Governing the Commons: The Evolution of Institutions for Collective Action. Supra, note 3 p. 93 94; and Henry, A. D. and T. Dietz. Information, networks, and the complexity of trust in commons governance. International Journal of the Commons. 2011. Vol. 5(2), pp. $188-212$.
} 
coordinated space activity. The regulatory shall take into consideration the merits of those objections as well allow the applying actor to state its case to defend the undertaking of this endeavour; equitably balancing the interests of launching operator with the views of space community and its legislative aim to protect the orbital environment. If the arguments of the space sector succeed, the Association will refuse to grant the launching license and thus prohibiting the endeavour.

The DEDA is an innovative tool that distinguishes itself from international space law in the sense that they are laws of nations, created between and directly applicable only to state parties to the treaties. It is a legal mechanism that includes commercial enterprises and private space enthusiasts, recognising that these operators are too 'subjects' to the law as well as users of the space environment and, like states, should be participate in decision-making outcomes affecting the mutual interests in the access and use of space. Furthermore, the DEDA contributes to the TCBMs for outer space activities. Space launchers across the global have knowledge of planned missions, possessing information pertaining to the launch, orbit and the nature and purpose of the activity. The "public consultation and participatory consultation" obligation combines a democratic component allowing the space community to challenge the organised activity from being carried out. It is a suitable deterrence tool to incentivise rule-compliance and restrain appropriators from behaving and acting opportunistically. Together, the ASA and such TCBMs as the DEDA could over time build a cooperative management arrangement that excludes unauthorised access by free-riders; that builds a system of effective communication and coordination between users; and that fosters trust and confidence among the community. The sum of such institutional regime could crystallise a collective duty on the appropriators to assume collective responsibility and accountability for the sustainable management and preservation of the Space Commons.

\subsubsection{Principle 2: Congruence between appropriation and provision rules and local conditions}

Ostrom's research shows that clear rule defining the boundaries of the CPR itself and the individuals who have authorised access and rights to appropriate from that resource are simply not enough for a successful and robust institutional regime. Assuming that the exclusionary rules under Principle 1 are effective, it is still possible for the limited number of appropriators who are authorised to enter the CPR to increase their appropriation activities of the resource units so that the cost of appropriation exceeds the benefits from the appropriation process, or cause the environmental destruction of commons should the withdrawal rate exceed its regenerative capabilities. Ostrom states that these problems faced by commons users can be clustered into two broad classes: 'appropriation problems' and 'provision problems'. She recommends that, in addition to closing boundaries, rules limiting appropriation and, or, mandating provision are needed $\frac{152}{\text {. }}$.

'Appropriation problems' are concerned with the allocation of the limited available resources units. CPR appropriators are concerned with the effects that various methods of allocating those limited resources units will have on the net return obtained by the users. This underlying issue with appropriator problems is referred in the commons literature as 'rent disspitation'. Rents are dissipated when the marginal costs of appropriation exceed the marginal returns from the appropriation process. As

${ }^{152}$ Governing the Commons: The Evolution of Institutions for Collective Action. Supra, note 3 at p. 92. 
Ostrom explains, rent disspitation can occur because too many individuals are allowed to access and appropriate from the resource; because CPR users are allowed overexploit the resource by withdrawing more than the economically optimal quantities of resource units; or because appropriators overinvest in appropriation equipment. Accordingly, the key problem to be solved is how to allocate the fixed quantity of resource units in an efficient and economical manner so as to avoid rent disspitation and reduce uncertainty and conflict with the assignment of rights ${ }^{153}$.

'Provision problems' concern the effects of various ways of assigning responsibility for creating, improving, or maintaining the resource over time, as well as avoiding its destruction. Provision problems can be divided into two types: the supply-side and demand-side problems; and one or both may occur. The supply-side problem can result from self-serving appropriators free-riding on the efforts and performance of others in the construction of the resource itself and its maintenance. The demand-side problem involves regulating the withdrawal rate of the CPR users' appropriation activities, ensuring that the rate of exploitation does not exceed the rate of replenishment. Although problems suffered in every CPR to a greater or lesser extent, the occurrence of the appropriation and provision problems would manifest differently and would depend on the particular structure of the resource system, the rules in use, and the attributes of the individuals accessing and using the commons. The solutions or strategy adopted to solve the problems of appropriation and provision must be fashioned according to the peculiar attributes of the common resource concerned. As Ostrom writes: 'The underlying uniformities of all CPR situations relate to the non-separability of one's choice of strategy and the choices made by others, as well as the fact that solving provision problems depends on achieving adequate solutions to appropriation problems.... Many factors affect the strategic structure of a particular appropriation or provision problem, including the physical structure of a particular CPR, the technology available to the appropriators, the economic environment, and the sets of rules that affect the incentives that appropriators face. As Oliver stressed... "there is no one 'right' was to model collective action: different models imply different assumptions about the situations and lead to substantively different conclusions", 154 .

Whereas Ostrom recommends that rule-making decisions should fit the diversity of the resource concerned, the literature on the governance approach for space since 2009 , on the other hand, did not subscribe to this view. The conventional wisdom was that the regulatory framework for outer space should match the regimes which were designed for other global commons, arguing that space as with the other resource arenas as air, maritime and cyberspace (in other words, the internet) share two essential criteria. That is to say, it is a global commons meaning that space is not subject to claims of national sovereignty, and that the environmental pollution produced is transboundary. As these two criteria were satisfied, this was sufficient basis for commentators to conclude and uphold the conventional view, and state that other attributes peculiar to the Space Commons were irrelevant for consideration under their regime analyses. In the context of the space debris problem, for example, the literature argued that the regulatory structure and legislative instruments to manage congestion in near-Earth orbits through salvaging and remediation operations

\footnotetext{
${ }^{153}$ Ibid, p. 48.

${ }^{154}$ Ibid, pp. $49-50$.
} 
should model the approaches designed under the maritime law which dealt with such procedures for ships which were wreck at sea ${ }^{155}$.

Although governance comparisons with terrestrial, global resources can be insightful, it is argued that the differences with the physical structure of space as an extraterrestrial commons; its usage; the range of appropriators authorised to access and appropriate the space resource units; the space community's principles and norms in the use and exploration of outer space; and the flow of information about the space and its environment and communication among actors, are so significant that they cannot be disregarded from the institutional design ${ }^{156}$. These factors based on biophysical and socio-economic conditions are connected under a complex and interactive network. The problems of appropriation and provision would therefore occur differently in space as with each global commons if they are examined upon its own merits and, in turn, require different responses on how to effectively coordinate collective action and regulate and oversee the resource. Thus, sharing the rule-in-use designed from one domain to another may not yield the same outcomes and is not an appropriate strategy. The governance system and rule-in-use for the Space Commons must therefore be crafted according to its peculiar attributes.

\subsubsection{Principle 3: Collective-Choice Arrangements}

Following Ostrom's framework for institutional design, the third design principle is called the 'collective-choice arrangements'. Activities such as policymaking, management and adjudication of decisions occur at this institutional level. Collective-choice rules may be made at the international or national arena. They are used by resource appropriators themselves, their regulators or some external agency to design policies, that is the operational-level rules, about how a commons should be governed and managed. However, these outcomes are directly affected by the rules made at the constitutional-choice level. Though it creates the decision-making power, constitutional rules may also limit its scope by specifying who belongs in the collective-choice arrangement and has the authority to exercise the power and in what situations it can be used ${ }^{157}$. Under this principle, Ostrom provides that the appropriators who are most affected by the operational-rules are eligible to participant in developing and modifying the operational-rules ${ }^{158}$. Empirical studies shows that CPR institutions where resource appropriators participate in shaping and modifying operational rules are more likely to result in long-lasting and successful governance. Rules designed and implemented by external entities that do not directly access and use the commons concerned may not necessarily result to the sustainable management of that resource. Through theoretical and empirical evidence, Ostrom argues that a

\footnotetext{
${ }^{155}$ See, for instance: Jansentuliyana, N. Regulation of Space Salvage Operations: Possibilities for the Future. Journal of Space Law. 2005. Vol. 5, pp. 5 - 21; Fishman, C. Space Salvage: A Proposed Treaty Amendment to the Agreement on the Rescue and Astronauts, the Return of Astronauts and the Return of Objects Launched into Space. Virgina Journal of International Law. 1985 - 1986, Vol. 26, pp. 965 1000; and Mej1'a-Kaiser, M. Removal of hazardous space debris. In: Petlton, J.N. and R.S. Jakhu.

2010. Space Safety Regulations and Standards. Butterworth-Heinemann: Boston. Chapter 27, pp. 371 382.

${ }^{156}$ The Global Commons: Environmental and Technological Governance. Supra, note 50 at pp. $20-$ 43; and Ostrom, E. Background on the Institutional Analysis and Development Framework. The Policy Studies Journal. 2011. Vol. 39(1), pp. 7 - 27.

${ }^{157}$ Ibid, pp. 52 and 192.

${ }^{158}$ Governing the Commons: The Evolution of Institutions for Collective Action. Supra, note 3 at pp. 93 -94 .
} 
central agency, insufficiently resourced in accuracy of information, monitoring capabilities, sanctioning reliability and finances, could lack the required impetus to prescribe the behavioural relationships and roles among actors; constrain unwanted activity including the punishment for non-compliance; and shape expectations. Common users are more likely to understand the specific nuances of various situations and craft rules which better fit that resource system. Having membership and participation in the governance, Ostrom is also of the opinion that this would increase the likelihood that resource appropriators will follow the rules ${ }^{159}$.

Under the existing governance regime, "space law is bifurcating, ${ }^{160}$. As Lyall writes, '... the public international law of space and the law relating to the regulation of the commercial (and increasingly the private) use of space, are different spheres. The latter is the province of the legislatures and the administration of separate states. More and more states are undertaking space activities themselves, or are authorising private enterprise to do so ${ }^{, 161}$. In other words, there are two-levels of rule-making which design the collective-choice rules, and these policy-making decisions are carried out at the international and national arenas. At the first level - the international plane - there are three organisation within the United Nations system that are responsible for creation and development of international space law, that is the collective-choice rules, and so eligible to craft the operational rules on how to regulate and oversee the space commons ${ }^{162}$. These institutions are: the Conference of Disarmament (CD), the Committee on the Peaceful Uses of Outer Space (COPUOS), and the International Telecommunications Union (ITU). The second rule-making level is an added dimension that does not exists with common property regimes for terrestrial resource systems, and is an important attribute identifying the space regime. The underlying rationale for the inclusion of the national arena in collective-choice rules is upon the observation that members of international resource regimes are ordinarily state actors and whose national activities are carried out by governmental agencies or non-governmental entities, such as private individuals or commercial enterprises, who are nationals of that country ${ }^{163}$. Thus, the regulatory oversight over the operations undertaken and patterns of behaviour exhibited by non-state actors is required at the domestic level. It is by virtue of Article VI of the Outer Space Treaty and the ITU Radio Regulations which crystallise the second-level into the collectivechoice rules under the space governance regime. This provision delegates law-making authority to member states to transpose and give effect to the international instruments relating to space activities in municipal law. It further imposes responsibility of authorisation and continuous supervision for the launching and mission activities carried out by nationals belonging to that country in order to ensure that to obey and comply with the state's international obligations as agreed at the constitutional-choice level, and liability for breach of any such obligation.

By applying Ostrom's third design principle to the existing governance arrangement for outer space, it is argued that none of the three institutions responsible

\footnotetext{
${ }^{159}$ Governing the Commons: The Evolution of Institutions for Collective Action. Supra, note 3 at pp. 8 -12 and $92-93$.

${ }^{160}$ Lyall, F. Book review - Cologne Commentary on Space Law (Vol 1): Outer Space Treaty, S. Hobe, B.Schmidt - Tedd, K-U Shrogl (eds). G.M. Gob (Assist. Ed), Carl-Heymanns. Space Policy. DOI: 10.1016/j.spacepol.2011.09.002.

${ }^{161}$ Ibid.

${ }^{162}$ Lyall. Supra, note 161.

${ }^{163}$ Young, O.R. The Problem of Scale in Human/Environment Relationships. In: Keohane, R.O. and E. Ostrom. (eds.). Local Commons and Global Interdependence: Heterogeneity and Coordination in Two Domains. 1995. SAGE Publications Ltd: London. Chapter 2 at p. 32.
} 
for the creation and development of international space law fully satisfy it. As Weeden and Chow write, '... both COPUOS and the CD have been used to create binding agreements and operate by consensus, but exclude private entities from being formal members, limit the role of non-governmental entities, and have strict limits on their mandate (non-military for COPUOS, disarmament for the CD). The ITU broadly includes states and private companies, but does not operate by consensus and does not possess any power of enforcement or ability to impose sanctions against violators of its rules and regulations, ${ }^{164}$. Membership and participation in the existing institutional regime is limited to internationally-recognised sovereign states. A nation-state can exercise its free choice and be a 'signatory state', 'party state' or a 'third state' to the regulatory arrangements designed by the institutions; thereby affecting the commitments and obligations assumed under international space law. Non-state actors are outside therefore the mainstream institutions despite the burgeoning commercial and private space industry. It could be said that the exclusion of commercial and private actors from membership and participation in the decision-making process at the international plane contravenes Article I of the Outer Space Treaty taken in conjunction with Article VI. Article I emphasises that outer space, including the Moon and celestial bodies, is the 'province of all mankind' and shall be free for exploration and use by all states without discrimination of any kind and on the basis of equality. Article VI of the Outer Space Treaty imposes international responsibility for national activities outer space, including the Moon and other celestial bodies, whether such activities are carried on by governmental agencies or by nongovernmental entities. From these provisions, it is clear that drafters of the treaty envisioned that accessibility and utility of outer space would be harnessed by different classes of space operators, including governmental agencies and private launchers, and not limited to spacefaring nations. Accordingly, by adopting a political legal perspective, Article I taken in conjunction with Article VI of the Outer Space Treaty 'provides sufficient legal grounds for claims to full and effective participation by all members of the international community in the decision-making process relating to outer space' (emphasis added) ${ }^{165}$.

There are, nonetheless, recent examples illustrating that non-state actors can influence, and have done so, space governance outside the CD, COPUOS and ITU as well as international law relating to space activities. One such instance involves the three major satellite operators, INTELSAT, SES and INMARSAT, establishing the Space Data Association in $2009^{166}$. According to its charter, the SDA's primary aims are 'to seek and facilitate improvements in the safety and integrity of satellite operations through wider and improved coordination among satellite operators and to facilitate improved management of the shared resources of the space environment and

\footnotetext{
${ }^{164}$ Weeden, B.C. and T. Chow. Taking a common-pool resources approach to space sustainability: A framework and potential policies. Space Policy, 2012. Available from: http://dx.doi.org/10.1016/j.spacepol.2012.06.004. Date Accessed: 05/07/2012.

${ }^{165}$ Danilenko, G.M. Outer space and the multilateral treaty-making process. 1989. High Technology Law Journal. Vol. 4, pp. 217 - 247 at p. 223.

${ }^{166}$ de Selding, P.B. Satellite operators solicit bids to create orbital database. SpaceNews.com. November 18, 2009. Available from: http://www.spacenews.com/satellite telecom/091118-satellitefirms-moving-ahead-orbital-database.html. Date Accessed: 20/11/2009. That date has been moved back to December 2010. See: Space Data Association Limited. Satellite industry leaders establish new space association. Commercial Space Watch. December 2, 2009. Available from: http://www.comspacewatch.com/news/viewpr.rss.html?pid=29738. Date Accessed: 02/12/2009.
} 
the [radio frequency] spectrum ${ }^{167}$. This event indicates that the commercial sector is assuming joint responsibility for the long-term preservation of the orbits, and leading the space community to promptly address the orbital debris problem with pragmatic and effective initiatives before the quality and safety of the space environment degrades to such an extent that LEO and GEO become unusable. It also suggests that non-state actors are losing confidence with the CD, COPUOS and ITU and the nationstates respectively belonging to those institutions to negotiate and reach international consensus for the development and implementation of appropriate legally-binding instruments and other mechanisms which could adequately manage space congestion. Commercial and private entities are therefore participating, albeit indirectly, in decision-making outcomes which can affect constitutional-choice rules.

To satisfy the third design principle, the Association of Space Appropriators (ASA) as proposed above should include commercial space sector and private entities in its institutional forum. It is suggested that such membership criteria, consisting both governmental and non-governmental entities collectively representing the space community, could optimally regulate the patterns of behaviour of and oversee space operations carried out by state and non-state users. This, in turn, could build an effective system of communication, and enhance trust and confidence among members of the community in their cooperative efforts to govern space for its longterm safety and sustainability for current and future actors. However, this recommendation should not be interpreted as saying that every space user, whether nation-state or non-state entity, is a space appropriator and satisfies the membership criteria for the ASA. As Stern warned above, if Ostrom's third principle was to be given its literal meaning for global commons, it would mean generate absurdities to the extent that the entire human population would be regarded as a resource appropriator $^{168}$. To this end, Principle 3 must be read purposively taking into account the type of commons in question whether local or global, and its scale whether small or large. For large-scale, global resource systems, Stern's reinterpretation should be adopted: 'Ensure meaningful participation of the range of interested and affected parties in developing rules, 169 .

Accordingly, appropriators of the Space Commons and thus membership eligibility to the ASA should be limited to and reserved for 'meaningful' actors. The word 'meaningful' has no definition; rather, it prescribes some qualifying attributes the applicant actor must satisfy before membership to the Association is considered. These prerequisites establish a common bond with other members, emphasising that the space community 'are tied together in a lattice of interdependence so long as they continue to share a single CPR ${ }^{170}$. In other words, an entity's individual choice of behaviour and utilisation of near-Earth orbits jointly affects the remaining members of the community with their current and future operations. This observation is significant as it contributes to the aim of the ASA to decide policy outcomes which are conducive to collective action by vesting rule-making authority to the range of appropriators who are directly interested and most affected by how space is accessed and used and by whom. For an actor to be considered as a space appropriator, there are two most obvious yet essential qualifications that must be established. The first is that the applicant possesses the necessary financial and technical capabilities to enter

\footnotetext{
${ }^{167}$ Space Data Association. SDA Overview. Available from: http://www.space-data.org/sda/about/sdaoverview/. Date Accessed: 05/04/2012.

${ }^{168}$ Stern. Supra, note 105 at p. 221.

${ }^{169}$ Ibid.

${ }^{170}$ Governing the Commons: The Evolution of Institutions for Collective Action. Supra, note 3 p. 38.
} 
space. The second requirement is that the entity's space interests and returns, whether economic, scientific knowledge, technological development or otherwise, are directly generated from their usage of space. By virtue of these two requirements, spacefaring nations like the U.S. Russian and China would be included membership as they have independent launching capabilities and space assets of great sums of money in space. By the same token, space-competent countries that do not have independent capabilities but operate their own space objects are also space appropriators. A state like Madagascar that is yet to be a manufacturer or an operator of aerospace objects, and as a result does not have any space law or regulations regarding space objects, would however be outside the common bond that defines and identifies space appropriators ${ }^{171}$. Governmental entities like NASA and intergovernmental organisations like the European Space Agency (ESA) are within the class of space appropriators and permitted membership to the Association. In light of the burgeoning commercial space sector, companies like Virgin Galactic and SpaceX and satellite operators as INTELSAT and INMARSAT in GEO are eligible space appropriators for the ASA.

Nonetheless, to ensure that scope of space appropriators is controlled further, a third condition should be added: the applicant must have a continuing space presence. This attribute is suggested as a response to the event that involved both Tonga and INTELSAT in the 1990s, acting as a regulatory mechanism against self-serving state and non-state actors from abusing the rights vested under Article I of the Outer Space Treaty which purports that outer space and its environment shall be free to access, use and explore without discrimination and on the basis of equality, by claiming status as a space appropriator and rights to participate in the decision-making outcomes at the ASA. Tonga submitted applications to the ITU for the allocation of sixteen geostationary orbital slots over the Pacific Ocean. INTELSAT objected to the allocation of those orbital positions, arguing that that not only did those sixteen filed satellite applications far exceed the number required to address its own national communications needs, but Tonga was an unlikely candidate to enter the global telecommunication sectors ${ }^{172}$. Its economy was heavily based on agriculture, forestry and fishing. Its gross domestic product was approximately $\$ 70$ million, much of which was state aid from other countries however, and was not sufficient to develop independent launching capabilities and coordinate space programmes. INTELSAT challenged the incorporation of Tongasat, claiming that it purpose was not to utilise the orbits for improved domestic communications but was engineered as a speculative venture for profit by leasing the allocation rights of those slots to the highest bidder. There was the concern that the ITU's ruling in favour of Tonga for all sixteen slots might have had wider implications on the global telecommunications market. That is, the emergence of a new market involving the selling of geostationary positions which would lead to the potential abuse of the "first come, first serve" principle by lessdeveloped countries. According to this principle, the right to use a radio frequency and orbital segment results from their registration with the ITU and not from the actual placement of a satellite in the desired GEO $\operatorname{slot}^{173}$. The development of such a market could have incentivised non-space capable countries to enter the telecommunications markets through 'paper satellites'. These states would race to file

\footnotetext{
${ }^{171}$ A/AC.105/635/Add.10 of 21 January 2004.

${ }^{172}$ A Lost Connection: Geostationary Satellite Network and the International Telecommunications Union.Supra, note 2 at pp. $1120-1121$.

${ }^{173}$ Doyle, S.E. Space Law and the Geostationary Orbit: The ITU's WARC-ORB-85-88 Concluded. Journal of Space Law. 1989. Vol. 17, pp. 13 - 21.
} 
as many satellite applications as their financial resources to cover the costs of applications would permit and as quickly as possible; hereby claiming registered title to those positions and excluding others from their utility ${ }^{174}$. Aware that they lack of space-competency to make use of GEO, developing nations may sell the 'paper satellites' and associated rights to others in exchange for economic gain ${ }^{175}$. To that end, INTELSAT claimed that Tonga's actual intentions in the incorporation of Tongasat contravened the vision of the telecommunications regulator for a robust international satellite communication network that provided equitable access to all countries. Owing such pressure exerted, Tonga later imposed a self-restraint to appease the community of satellite operators by reducing the number of satellite applications from sixteen to six. It should be noted that the ITU, an institution whose regulations are largely technical provisions and non-legally binding, could not enforce a reduction of applications under its own regime in order to constraint Tonga's individualistic activity since it was a sovereign administration, nor enforce the selfrestraint should the nation reneged on its promise. Despite its voluntary reduction, Tonga's claim for six slots was still in far exceed of the number required to address its own national communications needs ${ }^{176}$. The third membership requirement is therefore an attempt to detect applications submitted by 'free-riders' and prevent such applicants from acquiring membership status and related rights. In other words, users lack standing as space appropriators because their presence is fleeting, or is in the shadow of an eligible space appropriator who substantially contributed to the launching, maintenance and operation of the space object. It is hoped that this third membership qualification would avert self-opportunistic state and non-state actors from gaining status as an appropriator in order to legitimatise their endeavours to excessively appropriate the limited orbital capacity beyond their domestic needs and space capabilities. It also means that spaceflights participants who paid for journeys to the orbits, including affluent persons who enjoy a short stay on the International Space Station, are excluded from the class of space appropriator and in turn membership to the Association. Furthermore, ultimate consumers of space-based services on Earth are not space appropriators. As Meek writes: 'These users/consumers are at least one step removed from the resource appropriators. Their interests may be met by their space service providers (appropriators), without extending to them participatory rights, responsibilities and governance roles. Including users/consumers in space governance mechanisms will be so unwieldy as to ensure total gridlock, regardless of the decision-making procedures. Thus, it seems prudent to limit the space appropriators to spacefaring states, space-capable states and perhaps the space satellite service providers ${ }^{177}$.

\subsubsection{Principle 4: Monitoring to ensure rule-compliance}

Principle 4 provides that there must be a system of monitoring for a robust and successful CPR arrangement. Here, monitors are responsible for reviewing the conditions of the commons and overseeing operational use to ensure that such appropriation activities and patterns behaviours exhibited by resource appropriators

\footnotetext{
${ }^{174}$ Roberts. Supra, note 2 at pp. $1119-1120$.

${ }^{175}$ Roberts. Ibid, pp. 1120 - 1121; and Ezor, J.I. Costs Overhead: Tonga's claiming of sixteen geostationary orbital sites and the implications for U.S. Space Policy. Law and Policy in International Business. 1992 - 1993. Vol. 24, pp. $915-941$ at p. 924 at pp. $933-935$.

${ }^{176}$ Roberts. Ibid.

${ }^{177}$ Meek Supra, note 132.
} 
adhere to the rules-in-use. Ostrom states that these monitors are accountable to the appropriators or are resource appropriators themselves ${ }^{178}$.

As argued above, the existing space governance regime is bifurcating ${ }^{179}$. There are accordingly two-levels which are nested under the space law regime where rulemaking decisions and regulatory oversight of actors' activities and behaviours occur; namely, the international and national arenas ${ }^{180}$. At the first level - the international plane - the CD, the COPUOS and the ITU are participants in the collective-choice rules, and so eligible to craft the operational rules on how to regulate and oversee the space commons ${ }^{181}$. These three institutions are responsible for the creation and development of international space law. They also provide an international forum for member states to address common challenges and related problems affecting the final frontier in a cooperative and peaceful manner. From their respective efforts, it is argued that there are two space regimes operating simultaneously: one particular; and one general ${ }^{182}$. The particular regime involves the 'telecommunication' regime' designed by the ITU. Its regulatory competency is strictly restricted to the management and allocation of the radio frequencies to satellite actors operating activities in geostationary orbit ${ }^{183}$. The general regime is jointly developed by the CD and COPUOS, which shall be called the 'outer space regime'. Its regulatory scope is much greater than the telecommunications regime, and governs the use and exploration of not only near-Earth orbits but also the Moon and other celestial bodies. The CD, COPUOS and ITU are therefore deliberative organs within the UN structure to foster international relations and peaceful cooperation among nation-states in the use and exploration of outer space, and exercise limited regulatory competencies to achieve this purpose. Regulatory oversight of the activities and behaviour of state space actors and intergovernmental organisations, on the other hand, is not a competency of the CD, COPUOS or ITU. The outer space and telecommunications regimes, respectively, delegates such responsibilities to the member states, vesting certain enforcement powers to ensure rule-compliance and prescribing a liability scheme in the event of rule infractions. With respect to the outer space regime, this is argument is reinforced by Articles VI and VII of the Outer Space Treaty, including the Liability Convention which bolster the rules under the latter provision. Article VII purports that states parties to the Outer Space Treaty shall bear international responsibility for national activities in outer space, including the Moon and other celestial bodies, whether such activities are carried on by governmental agencies or by non-governmental entities, and for assuring that national activities are carried out in conformity with the provisions set forth in the present Treaty. Article VII provides: 'Each State Party to the Treaty that launches or procures the launching of an object into outer space, including the Moon and other celestial bodies, and each State Party from whose territory or facility an object is launched, is internationally liable for damage to another State Party to the Treaty or to its natural or juridical persons by such object or its component parts on the Earth, in air space or in outer space, including the Moon and other celestial bodies'. The rules under Article VII are

\footnotetext{
${ }^{178}$ Governing the Commons: The Evolution of Institutions for Collective Action. Supra, note 2 at p. 94.

${ }^{179}$ Lyall. Supra, note 161.

${ }^{180}$ The Problem of Scale in Human/Environment Relationships. Supra, note 162 at p. 32.

${ }^{181}$ Lyall. Supra, note 161.

${ }^{182}$ Buck. Supra, note 136 at p. 138.

${ }^{183}$ First Session of the World Administrative Radio Conference on the Use of Geostationary Satellite Orbit and the Planning of the Space Services Utilizing it. Letter dated 16 October 1985 from the Secretary-General of the ITU. Addressed to the Secretary-General of the UN. U.N. Doc. A/AC.105/360. November 6, 1985.
} 
promulgated under the Liability Convention which sets out the rules and procedures concerning the liability for damage caused by space objects and to ensure the prompt payment under the terms of the Convention of a full and equitable measure of compensation to claimants. If no settlement of claim been reached through diplomatic negotiations, a Claims Commission can be convened at the request instigation of either the claimant or defendant parties ${ }^{184}$. An innovative provision of the Liability Convention is that if the injured state does not choose to present the claim, there are two other possibilities of governmental intervention ${ }^{185}$.

Under the telecommunications regime, the ITU's regulatory activity is 'pervaded by a voluntaristic norm, ${ }^{186}$. '[It] acts as an efficiency-enhancing resource through which sovereign states attempt to avoid potential usage conflicts and as a convenient forum for resolving disputes that arise ${ }^{187}$. In spite of providing a regulatory regime for the telecommunications market, the Union lacks the competency to enforce its own rules and regulations over sovereign states through such formal mechanisms as sanctioning or coercive measures ${ }^{188}$. This also includes challenging the word of an administration when that administration is describing its own space activity at the time of filing satellite application for registration if it is suspicions as to the true nature of the operation ${ }^{189}$. Monitoring compliance to the regulations and actual usage of the geostationary orbit and frequency bands are left to the resource actors themselves. There are many legal scholars with favourable views towards the appropriateness and efficacy in the use of such system of self-governance and self-monitoring. Soroos, for example, is of the opinions that '...the rate of compliance with ITU radio regulations is relatively high because of strong international pressures against violating them, and, in some case, because of their selfenforcing nature; if one wants to communicate, one must have compatible equipment and avoid interference by not encroaching on the frequencies used by others ${ }^{190}$.

The second rule-making and monitoring level is an added dimension that does not exists with common property regimes for terrestrial resource systems, and is an important attribute identifying the space regime. The underlying rationale for the inclusion of the national arena in collective-choice rules is upon the observation that members of international resource regimes are ordinarily state actors and whose national activities are carried out by governmental agencies or non-governmental entities, such as private individuals or commercial enterprises, who are nationals of that country ${ }^{191}$. Thus, the regulatory oversight over the operations undertaken and patterns of behaviour exhibited by non-state actors is required at the domestic level. It is by virtue of Article VI of the Outer Space Treaty and the ITU Radio Regulations

\footnotetext{
${ }^{184}$ Article XIV of the Liability Convention. See: Convention on International Liability for Damage Caused by Space Objects, adopted by the General Assembly in its resolution 2777 (XXVI), opened for signature on 29 March 1972, entered into force on 1 September 1972.

${ }^{185}$ Article VIII(2) and (3) of the Liability Convention.

${ }^{186}$ Vogler. Supra, note 21 at p. 114.

${ }^{187}$ Roberts, L.D. Supra, note 67 at p. 1111.

${ }^{188}$ Jakhu. Supra 124 at p. 181.

189 de Selding, P.B. Iran's Claims About Satellite Service Try International Regulatory Regime. SpaceNews.com. April 8, 2011. Available from: http://www.spacenews.com/satellite telecom/110408iran-claims-sat-regulatory-regime.html. Date Accessed: 15/08/2011; and de Selding, P.B. Talks, Mediation Fail To Settle Iran-France Frequency Dispute. Available from: http://www.spacenews.com/satellite telecom/110715-talks-fail-settle-iran-france-dispute.html. Date Accessed: 15/08/2011.

${ }^{190}$ Soroos. Supra, note 39 at p. 670. See also Vogler for contrary opinions: Vogler. Supra, note 21 at p. 117.

${ }^{191}$ The Problem of Scale in Human/Environment Relationships. Supra, note 163 at p. 32.
} 
which crystallise the second-level into the collective-choice rules under the space governance regime. This provision delegates law-making authority to member states to transpose and give effect to the international instruments relating to space activities in municipal law. It further imposes responsibility of authorisation and continuous supervision for the launching and mission activities carried out by non-governmental entities belonging to that country in order to ensure that to obey and comply with the state's international obligations, and liability for breach of any such obligation.

In light Ostrom's design principles, Principle 4 is satisfied. Under the space regime, state and non-state appropriators are assuming collective responsibility for overseeing the activities and patterns of behaviour exhibited by the space community, and have developed a system of space monitoring. After witnessing two intentional satellite destructions and accidental collision, the community have heavily invested in space surveillance networks (SSNs) to combat against the growing space debris population from congesting near-Earth orbits. SSNs have the ability to detect and track space objects; distinguish which objects are natural and man-made; identify artificial objects as functional or inactive space vehicles, or orbital debris; and calculate its orbital positions, velocities and trajectories ${ }^{192}$. Such data is referred in the literature as space situational awareness (SSA). With such comprehensive information, it 'enables decision-makers to rapidly and effectively select courses of action to ensure our sustained freedom of action and safety in what is clearly a contested environment ${ }^{193}$. The U.S. is regarded as the most capable and robust network system than other States' $\mathrm{SSN}^{194}$, having 29 ground-based sensors positioned globally ${ }^{195}$. Such countries as France, Germany, Japan and Russian have in place their own tracking networks, but they are limited in its abilities. These network systems are not interconnected to enable the sharing of information ${ }^{196}$.To supplement their own data, these countries must rely upon the information generated by America's network ${ }^{197}$. Nonetheless, there are critical gaps in the current system to fully identify and track all space objects analyse and predict conjunctions, and to protect US space assets $^{198}$. However, to overcome these shortcomings, an on-orbit sensor called Space Fence has been developed and thus enhances the country's capabilities to detect objects in LEO and medium-Earth Orbit by tenfold ${ }^{199}$ and to provide a more expansive coverage in the Southern hemisphere ${ }^{200}$.

\footnotetext{
${ }^{192}$ U.S. House of Representatives Committee on Science and Technology's Subcommittee on Space and Aeronautics. Hearing Charter. Keeping the space environment safe for civil and commercial users. April 28, 2009 at pp. 1 and 8. Available from:

http://democrats.science.house.gov/Media/file/Commdocs/hearings/2009/Space/28apr/Hearing_Charter .pdf. Date Accessed: 14/09/2009. Hereafter referred to as the 'Committee on Space Environment Safety Report'.

${ }^{193}$ U.S. House of Representatives Committee on Science and Technology's Subcommittee on Space and Aeronautics. Statement of Lieutenant General Larry James Commander Joint Functional Component Command for space on keeping the space environment safe for civil and commercial users. April 28, 2009 at p. 7. Available from: http://democrats.science.house.gov/Media/file/Commdocs/hearings/2009/Space/28apr/James_Testimon y.pdf. Date Accessed: 14/09/2009.

${ }^{194}$ Ibid.

${ }^{195}$ Committee on Space Environment Safety Report. Supra, note 192 at pp. 2 and 8.

${ }^{196}$ Ibid, p. 2.

${ }^{197}$ Lieutenant General Larry James. Supra, note 193 at p. 8.

${ }^{198}$ Ibid, p. 8.

${ }^{199}$ Committee on Space Environment Safety Report. Supra, note 192 at p. 10.

${ }^{200}$ Lieutenant General Larry James. Supra, note 193 at p. 8.
} 
Other nation-states and commercial companies, whether U.S. nationals or not, are able to gain access to services and SSA support from the U.S. SSN by virtue of the Commercial and Foreign Entities Program (CFE) following the passage of section 913 of the National Defense Authorization Act of $2004^{201}$. That section vests discretionary, statutory authority to the Secretary of Defense to "carry out a pilot program to determine the feasibility and desirability of providing to non-United States Government entities space surveillance data support ${ }^{202}$. The Secretary delegated that statutory duty to implement a programme to the Secretary of the Air Force Space Command (AFSC) in October $2004^{203}$. That program was to end on September 30, 2010 but the passage of the National Defense Authorization Act for Fiscal Year 2010 transformed the CFE from a pilot to a permanent program ${ }^{204}$. Further, on January 4 , 2010, it was announced that the AFSC transferred its responsibility for sharing SSA and analysis with satellite operators to the U.S. Strategic Command (USSTRATCOM), which shall continue to evolve the programme in order to provide more services to more customers ${ }^{205}$.

However, the range for non-United States government entities eligible to access such space surveillance services and support from the CFE Program is restricted, and subject to an agreement. Section 2274(b), Chapter 35 in Title 10 of the United States Code states: 'Under such a pilot program, the Secretary may provide to a non- United States Government entity, subject to an agreement ..., the following: (1) Satellite tracking services from assets owned or controlled by the Department of Defense, but only if the Secretary determines, in the case of any such agreement, that providing such services to that entity is in the national security interests of the United States. (2) Space surveillance data and the analysis of space surveillance data, but only if the Secretary determines, in the case of any such agreement, that providing such data and analysis to that entity is in the national security interests of the United States'. The agreement is between the USSTRATCOM and the eligible space user, and consists of two conditions before any space surveillance support is offered ${ }^{206}$. First, the space operator must agree to pay an amount that the Command determines necessary to reimburse the Department for the cost of support under the agreement ${ }^{207}$. The second is that that actor must agree not to transfer any data or technical information received under the agreement, including the analysis of tracking data, to any other entity without the express approval of the USSTRATCOM ${ }^{208}$.

In addition to the agreement, space surveillance data is provided the U.S. Government on the www.space-track.org website. This website, which was previously available from NASA's Orbital Information Group website ${ }^{209}$, provides approved accountholders with unclassified, current data on catalogued space objects

\footnotetext{
${ }^{201}$ Public Law 108-136, 117 Stat 1392, H.R. 1588. November 24, 2003. This Act is largely codified under 10 U.S.C.A. $\$ 2274$ as amended (Thomson/West, 2010).

${ }^{202} 10$ U.S.C.A. $\$ 2274$ (a) (Thomson/West, 2010).

${ }^{203}$ Committee on Space Environment Safety Report. Supra, note 192 at pp. $11-12$.

${ }^{204}$ Section 912(a) of the National Defense Authorization Act for Fiscal Year 2010. Public Law 111-86, 123 Stat 2190, H.R. 2647. October 28, 2009 (Thomson/West, 2010).

${ }^{205}$ U.S. Strategic Command. Commercial \& Foreign Pilot Program transition to U.S. Strategic

Command. U.S. Strategic Command Public Affairs. January 4, 2010. Available from: http://www.stratcom.mil/news/article/137/commercial_foreign_entities_pilot_program_transitions_to U.S._strategic_comman. Date Accessed: 04/01/2010.

20610 U.S.C.A. $\S 2274$ (d) (Thomson/West, 2010).

${ }^{207}$ Ibid, $\S 2274(\mathrm{f})(1)$.

${ }^{208}$ Ibid, § 2274(d)(2).

${ }^{209}$ Committee on Space Environment Safety Report. Supra, note 192 at pp. $11-12$.
} 
without charge ${ }^{210}$. There are 'over 37,000 users spanning over 110 countries with $75 \%$ of the users coming from the US, Canada, France, Germany, United Kingdom, and Australia' ${ }^{211}$.

Non-governmental entities are contributing to the international effort in providing effective space surveillance services and data by establishing their own networks. As discussed earlier, INTELSAT, IMARSAT and SES, the three largest commercial satellite operators, established the Space Data Association (SDA) in 2010. Even amateurs from the astronomy community have been asked by governmental agencies to volunteer in the tracking and monitoring of debris fragments $^{212}$.

The scientific advancement of SSA and the formation of agreements between state and non-state space users for conjunction analysis data is another TCBM. They foster international cooperation in the peaceful use and exploration of outer space, as well as enhancing trust and confidence among the members of the community through a mutual interest in controlling the population growth of debris and minimising the risk of near-Earth orbits becoming unusable. Here, there are two distinct types encouraged: trust in action and trust in information. Both are equally important as the other for the successful global governance regime as they both influence actors' decision-making outcomes and strategic behaviour when interacting with the commons. As Henry and Dietz, 'Trust is an important determinant of sustainability outcomes because it influences strategic interaction between actors whose individual incentives are not necessarily in alignment with that of the collective. Trust is crucial to collective action since cooperative behavior - acting outside of one's narrow selfinterest in order to advance the interests of the group - carries the risk that others will not cooperate, leaving cooperators paying all the costs of cooperation without receiving commensurate benefits. Thus, in order to make the prediction that an actor will behave cooperatively, one must also assume that they have some degree of trust that the other involved in their decision-making situation will also cooperate ${ }^{213}$. With this in mind, the current system of space monitoring is a deterrence mechanism restraining users from acting individualistically for their short-term gains at the expense of the long-term interests of the community for the safety and sustainability of the space environment. It also has the capability to instil a sense of environmental responsibility on each space operator, and hold them accountable for their conducts and activities in outer space. This is because every launcher is consciously aware that their activities are monitored and documented, and that public condemnation is threatened if the space community suspects that that actor is exhibiting irresponsible behaviour by undertaking risky and unsafe operations. To that end, this may encourage actors to act with due diligence throughout the launch, mission and disposal stages of the planned mission by ensuring that the space object is safe and reliable for launching; that the operation is an acceptable activity and is executed responsibly; and that the space object is disposed according to the non-legally binding space debris mitigation guidelines issued respectively by the Inter-Agency Space Debris Coordination Committee (IADC) and COPUOS.

\footnotetext{
${ }^{210}$ Lieutenant General Larry James. Supra, note 193at p. 4.

${ }^{211}$ Ibid, pp. $5-6$.

${ }^{212}$ Coldewey, D. DARPA enlists amateur astronomers to track space junk. NBCNews.com. Available from: http://www.nbcnews.com/technology/darpa-enlists-amateur-astronomers-track-space-junk1C7009960. Date Accessed: 13/11/2012.

${ }^{213}$ Henry and Dietz. Supra, note 151 at p. 189.
} 
Nonetheless, Ostrom's original design principle for local CPRs raises challenges with applied to the Space Commons. One such challenge is that the current space monitoring is technically difficult and requires expensive and highly technical equipment. Only the major space players have the 'capacity', which is here measured on the availability of financial, technical, human and other resources necessary, to create and maintain a robust space surveillance network. A related concern is that if space surveillance services and conjunction analysis data are derived from a nationstate's SSN, such information must be restricted to an extent to ensure that that country's national security is not compromised. There is accordingly an incentive for countries with SSA capabilities like the U.S. to underreport or omit information which might relate to its military use or operations in space. A special challenge to the debris problem arises. Not every space object can be detected, tracked and catalogued. The size of the object might be too small, say less than ten centimetres, that existing SSA capabilities cannot monitor. Given its transboundary nature, a related problem is the difficulty of identifying and attributing responsible to the space polluter that generated those small debris pieces. In light of these challenges, Ostrom's principle must be adjusted accordingly. As opposed to internal monitoring system operated by resource appropriators themselves, it is suggested that an external system of monitoring that is independent from the space appropriators is required. The monitoring agency would be independent from the resource itself meaning that it is a not a space appropriator itself according to the requirements test explained above under Principle 3, and the monitors have no connection or relationship that ties them to any space actor. Since environmental degradation can increase from a single debris-making event, the agency would have an on-going commitment to invest in science and technology to gain a greater understanding of outer space and its environment; how actors interact with the resource and are affected by its use; and how to effectively communicate SSA data to operators. Such improved understandings and developments in surveillance networks would enhance space monitoring and sanctioning. To ensure accountability of its monitoring activities, the agency would be directly accountable to the ASA which is represented by space appropriators who have been elected membership and so are the most interested and affected by the safety and sustainability of near-Earth orbits. Under this proposal, the costs of establishing and maintaining an external, independent monitoring agency would however be high. To that end, it is suggested that the ASA should create a fund whereby the financial costs for the monitoring network is apportioned between the state and non-state space actors. Further, the fund should provide fiscal packages to the monitoring agency for the purposes of stimulating scientific and technological research in providing improved space surveillance and SSA sharing.

\subsubsection{Principle 5: Graduated sanctions for non-compliance}

Commitment by the resource appropriators to comply with the operational rules is necessary for a robust and self-governing CPR arrangement. Principle 4 by itself is inadequacy to achieve this outcome. There must be a system of sanctioning that operates in parallel with the system of monitoring. Proponents of the conventional wisdom would argue that external coercion is needed to resolve the problem of commitment. Through theoretical models, they would presume that 'if individuals commit themselves to a contract whereby a stiff sanction ... will be imposed by an external enforcer to ensure compliance during all future time periods, then can make a 
credible commitment and obtain benefits that would not otherwise be attainable ${ }^{214}$. These models however provide no an explanation reasoning as to what motivates the external enforcer to monitor behaviour and impose sanctions. Disciples under this school of thought further postulate that individuals would have little to no incentive to participate in the monitoring and enforcing a set of rules, even if they are able to develop those rules themselves, because the costs of punishment are borne directly by the enforcer whilst the benefits from the punishment are distributed for all members to enjoy. Ostrom, on other hand, argues that the problem of commitment can be resolved without an external enforcer if resource appropriators develop their sanctioning activities and become enforcers themselves. Her field work illustrates that resource appropriators are indeed motivated to monitor rule-compliance and willing to impose sanctions against rule-breakers to keep conformance high, and that either the costs of monitoring are lower or the benefits to an individual are higher, or both, than initially presumed under the theoretical models ${ }^{215}$. To that end, the fifth design principle provides that resource appropriators must create their own internal enforcement to ensure compliance to the operational rules, deter actors from rule-breaking; and punish those who violate the rules-in-use. Ostrom is of the opinion that a system of graduate sanctions would decrease the costs of monitoring and enforcing the operational rules and increase the benefits shared from such activities and in turn motivate individuals, who believe that such system of monitoring and sanctioning would protect their respective interests in the commons, to make a declaration of selfcommitment to comply to the rule-in-use. It also means that 'once appropriators have made contingent self-commitments, they are then motivated to monitor other people's behaviour, at least from time to time, in order to assure themselves that others are following the rules most of the time ${ }^{216}$.

Under a system of graduate sanctions, the type of punishment an enforcer can impose onto rule-breakers is not limited to pecuniary penalties, therefore. As Ostrom writes, '[a] large monetary fine may not be needed to return an occasional to the fold of those who are quasi-voluntary with the rules. A large monetary fine imposed on a person facing an unusual problem may produce resentment and unwillingness to conform to the rules in the future. Graduate punishments ranging from insignificant fines all the way to banishment, applied in settings in which the sanctioners know a great deal about the personal circumstances of the other appropriators and the potential harm that could be created by excessive sanctions, may be far more effective than a major fine imposed on a first offender ${ }^{217}$. Here, Ostrom suggests that the punishment imposed must be proportionate to the nature and seriousness of the rule violation. Furthermore, aggravating and mitigating circumstances ought to be considered by the enforcer when deciding the appropriate sanction. For instance, repeated offenders would be severely punished to the extent that an exclusionary period or renunciation of their rights to access and use the resource would be applied. Whereas, appropriators of previously good character or the nature of the rule infraction is minor would be sanctioned with lenient punishments. The literature on environmental regulation suggests that 'smart regulation' strategies are also suitable for these types of rule-breakers. Such mechanism as 'naming-and-shaming' offenders in public is a sufficient incentive for individuals to renew their commitments to the $\mathrm{CPR}$ by proactively complying with the rules-in-use, and thus enable these

\footnotetext{
${ }^{214}$ Governing the Commons: The Evolution of Institutions for Collective Action. Supra, note 3 at p.44.

215 Ibid, pp. $44-46$ and $94-100$.

${ }^{216}$ Ibid, p. 100.

${ }^{217}$ Ibid, p. 98.
} 
appropriators to rebuild their reputations among the remaining members of the resource $^{218}$.

A system of graduated sanctions can promote governance certainty in the sense that enforcement and sanctioning activities are universal and invariable, which may encourage those individuals who expressed their conditional willingness to comply with the rules if free-riders are identified and punished to ensure that they do not gaining competitive advantages through their non-compliance ${ }^{219}$. Moreover, such a system is a form of flexible regulation that could help to avoid enforcement challenges which are shared at both the international and national levels. As Weeden and Chow state, ' $[\mathrm{m}]$ embers may be unwilling to commit to strict enforcement measures for fear of limiting freedom of action in the future or having to follow through on politically and unsavoury sanctions at a later date. As a result, many governance solutions lack any teeth at all, thereby rendering them ineffectual. Flexible penalties enable enforcement and give the regime some teeth without committing members to unduly harsh action for instances of future noncompliance, ${ }^{, 220}$. Some commentators such as Stern, on the hand, take the opposing view. Although graduated sanctions are just as important with global CPRs as local, they are difficult to implement at the international arena. They argue that sanctioning can be a major challenge under circumstances where the parties involved live in different countries with different legal and political systems, or live in different centuries $^{221}$. The problem is heightened by the fact that there is no centralised regulator policing the international plane or a system of law enforcement comprehensively developed. The United Nations Security Council may authorise the use of force to compel states to comply with its decisions, but only under certain circumstances. That is to say, there must be a prior act of aggression or the threat of such an act. Further, any of the Council's five permanent members - China, France, Russia, the United Kingdom, and the U.S. - can veto any such enforcement action. ${ }^{222}$.

With respect to the current space governance regime, concerns over the enforcement of international space law become apparent in light of the North Korea's rocket launch which was claimed to be carrying a satellite in December 2012, and was perceived by many as a long-range ballistic missile test. Given that the underlying purpose of the activity was opaque, there was no substantive basis for aggrieved state parties to the Outer Space Treaty in arguing that North Korea's launch was not for peaceful purposes and thus contravened Article I of that treaty. As a result, the space community could not use the possible breach as a ground to invoke Article 60(2) of the Vienna Convention of the Law of Treaties $1969^{223}$. This provision provides that, as a consequence of a material breach of a multilateral treaty by one of the parties entitles, 'the other parties by unanimous agreement to suspend the operation of the treaty in whole or in part to terminate it either: (i) in the relations between themselves and the defaulting State; or (ii) as between all the parties'. It is suggested that the enforcement of Article 60(2) would not have had terminate or suspend the operation

\footnotetext{
${ }^{218}$ See, for example: Bloor, M.; H. Sampson.; S. Baker.; D. Walker.; K.Dahlgren.; E. Wadsworth and P. James. Room for Manoeuvre? Regulatory Compliance in the Global Shipping Industry. Social \& Legal Studies. 2013, Vol. 22(2), pp. 171 - 189 at pp. 173 and $175-176$.

219 Ibid, p. 179.

${ }^{220}$ Weeden and Chow. Supra, note 164.

${ }^{221}$ Stern. Supra, note 105 p. 222.

${ }^{222}$ Shaw, M.N. 2012. International Law. $6^{\text {th }}$ ed. Cambridge University Press: Cambridge.

${ }^{223}$ Vienna Convention of the Law of Treaties 1969. Done at Vienna on 23 May 1969. Entered into force on 27 January 1980. United Nations, Treaty Series. Vol. 1155, p. 331.
} 
of the Outer Space Treaty ${ }^{224}$, but severed North's Korea's membership to the space governance regime; thus renouncing its rights under Article I of the Outer Space Treaty and, theoretically, excluding it from future access and usage of space. Instead, enforcement action was taken by the UN Security Council which adopted Resolution 2087 on January 22, 2013. This Resolution denounced North Korea's rocket launch stating that that launch used long-range ballistic missile technology and was in violation with earlier Resolutions which prohibited the state from possessing such technologies. Sanctions were also imposed individuals who were responsible with North Korea's launching activity under Resolution $2087^{225}$.

Nonetheless, recent space-related events as part of anti-satellite missile tests (ASATs) which involved China in 2007 and 2010 and the U.S. in 2008 do suggest that a system of graduated sanctions crystallised in an alternative institutional arrangement for space can effectively shape patterns of behaviour to ensure voluntary compliance to the operational rules, and deter space appropriators from acting opportunistically and contrary to those rules. The first event concerns the Chinese Fengyun-1C incident in 2007, which was described briefly above. Here, the People's Republic of China successfully performed an ASAT experiment but, although a state party to the Outer Space Treaty ${ }^{226}$, at the expense of adhering to its existing international obligation under Article IX of that treaty ${ }^{227}$. The Chinese government did not pre-emptively warn the space community with sufficient information nor held any international consultations, allowing the possibility of open debate, about the intentional destruction of its own weather satellite with other state parties ${ }^{228}$. The international community did not enforce sanctions against China for its irresponsible behaviour and acts after the test, however. Rather, certain national governments such Japan used diplomatic channels to publicly condemn China for resuming a military exercise which had not been conducted since 1985 - the era of the Cold War between the U.S. and the former Soviet Union - and thus broke a de facto rule against ASAT testing that was observed for more than 25 years $^{229}$.

The USA - 193 which was performed a year after the Fengyun - $1 C$ satellite destruction is the second space-related event. Unlike the Chinese's ASAT experiment, it appears that the U.S. recognised had a partial, but not complete, international obligation under Article IX of the Outer Space Treaty. By virtue of Ambassador Christina Rocca's statement to the Conference on Disarmament ${ }^{230}$, America

\footnotetext{
${ }^{224}$ Gabrynowicz, J.I. The Outer Space Treaty and Enhancing Space Security. In: Chapter 11, pp. 113 123 at p. 116. Available from:

http://kms1.isn.ethz.ch/serviceengine/Files/ISN/109001/ichaptersection_singledocument/2f8a3f679b8a-4615-b72f-18953b45d4aa/en/Chap11.pdf. Date Accessed: 03/07/2013.

${ }^{225}$ Hertzfeld and Li. Supra, note 142 at p. 93.

${ }^{226}$ China became a signatory to the Outer Space Treaty on December 30, 1983 in Washington. See: United Nations Office for Outer Space Affairs. Treaty Signatures. United Nations Office for Outer Space Affairs. Available from: http://www.oosa.unvienna.org/oosatdb/showTreatySignatures.do. Date Accessed: 21/01/2010.

${ }^{227}$ Mineiro. M.C. FY-1C and USA-193 ASAT Intercepts: An Assessment of Legal Obligations Under Article IX of the Outer Space Treaty. Journal of Space Law. 2008, Vol. 34, pp. 321 - 356 at p. 344.

${ }^{228}$ Ibid, p. 341; and Kan, S. CRS Report for Congress: China's Anti-Satellite Weapon Test. Congressional Research Service: The Library of Congress. April 23, 2007, pp. CRS-1 - CRS-6 at CRS2. Available from: http://www.fas.org/sgp/crs/row/RS22652.pdf. Date Accessed: 22/01/2011.

${ }^{229}$ Mineiro. Ibid, pp. 321 and 341; and Kan. Ibid at p. CRS-2. .

${ }^{230}$ Ambassador Christina Rocca. Statement to the Conference on Disarmament By Ambassador Christina Rocca U.S. Permanent Representative: Prevention of an Arms Race in Outer Space. Conference on Disarmament, First Session. February 13, 2007. Available from: http://www.reachingcriticalwill.org/political/cd/speeches07/1session/Feb13USA.pdf. Date Accessed:
} 
discharged the procedural duty of notifying states of the intentional destruction of its toxic defunct satellite prior to the launch of the missile, but did not satisfy the substantive requirement of holding an appropriate international consultation. Nonetheless, this act of informing states and space organisations shows America's responsible attitude and behaviour towards a safer and secure orbiting environment. Having regard to its consistent leadership in space competitiveness, the United States' conduct sets an influential trend, hopefully solidifying into an international custom for other nations to follow. In other words, American's conduct encourages space-capable countries to become transparent and publicly declare to the community from the outset of planning space operations that it bears the risk of producing debris.

China's failure to publicly consult with the community prior to the launch of the Fengyun-1C test heightened the country's opaque space policies, increased mistrust among space states actors, and undermined international peace and security. Against this background, it could be said that the U.S government's decision to publicly disclose the USA - 193 mission, indeed, had had an influential effect on China's subsequent behaviour and conducts in outer space. Whereas many would perceived that the third space -related event involved China performing its second ASAT experiment in 2010, the technical profile of the activity would not support such conclusion. Rather, the on-orbit rendezvous manoeuvres are consistent with docking procedures which would be required when China launches its space station.

Furthermore, unlike 2007, the country's behaviour and conduct during the launch, mission and end of the space activity was executed in a responsible manner. That is to say, the Chinese government were transparency with its planned mission publicly announced it prior to launch, and there is was no apparent damage to either satellites involved in or debris created from the on-orbit rendezvous manoeuvres ${ }^{231}$.

The three case studies above suggest that smart-regulation strategies have their place in fostering trust and reciprocity of actions in an arena where state and non-state actors are parties. Such mechanisms have the competency to dictate the patterns of the behaviour exhibited by individuals and incentivise them to comply with the rule-inuse through the fear of being detected of non-compliance and the consequences of such detection. To that end, and light of the New Space Age, it is recommended that a comprehensive system of graduated sanctions consisting of informal formal mechanisms and law enforcement should be developed by the ASA. Upon detection of non-compliance reported by the independent, external monitoring agency, it is onus of Association to enforce the operational rules by imposing the appropriation sanction that is proportionate to the seriousness and in context of the rule violation against the offending space user.

\subsubsection{Principle 6: Conflict-resolution mechanisms}

If individuals are going to follow rules over a long period of time, there must be some mechanisms for discussing and resolving what constitutes an infraction. To that

\footnotetext{
25/01/2011; and Ambassador Christina Rocca. Statement by Ambassador Christina Rocca, Permanent Representative of the United States to the Conference on Disarmament. Geneva, February 15, 2008. Available from: http://www.unog.ch/80256EDD006B8954/(httpAssets)/DE7EEEEB629D982FC12573F0004A1E07/\$f ile/Statement+by+Ambassador+Rocca.pdf. Date Accessed: 24/01/2011.

${ }^{231}$ Weeden, B. Dancing in the dark: The orbital rendezvous of SJ-12 and SJ-06F. The Space Review. August 30, 2010. Available from: http://www.thespacereview.com/article/1689/1. Date Accessed: 30/08/2010.
} 
end, Principle 6 provides for the development of conflict-resolution mechanisms.

Such mechanisms can be formal or informal, or a combination of both. In the context of local-scale CPRs, a simple informal conflict-resolution mechanism is where certain resource appropriators are selected as leaders to resolve the dispute through negotiation, conciliation or even arbitration with the parties involved. In legal scholarship, such informal mechanisms are known as 'alternative dispute resolution' (ADR) procedures which have been defined as: 'A set of practices and techniques that aim 1) to permit legal disputes to be resolved outside the courts for the benefit of all disputants; 2) to reduce the cost of conventional litigation and the delays to which it is ordinary subject; or 3) to prevent legal disputes that would otherwise likely brought to the courts ${ }^{232}$. Where, on the other hand, resource scarcity is so high, well-developed, formal mechanisms such as to the courts might be needed. To ensure rule-legitimacy and rule-compliance, it is essential that the dispute-resolution mechanisms are quick to access and low in costs, and are available to resource users and their officials to resolve conflicts among users or between users and officials ${ }^{233}$.

Ostrom's sixth design principle is not satisfied under the current space governance regime as it does not fully develop a framework for conflict-resolution ${ }^{234}$. Under the outer space regime, the space treaties does prescribe the ways in which to settled disputes, but are limited in their application and largely lays down procedural than substantive rules. The Outer Space Treaty sets forth the liability provisions under Articles VI and VII. Article VI provides that state parties to the treaty shall bear international responsibility for national activities whether such activities carried out by governmental agencies and non-governmental entities. Since non-governmental entities may access and use space only with the authorisation and continuing supervision of the relevant state, any liability of such an entity is imputed to the nation-state that authorised and supervised its activities. Article VII prescribes the nation-state that is subject to international responsibility for damage caused by its outer space activities state to a foreign state or national of that foreign state. That is to say, the launching state which is broadly defined in the Article as: 'Each State Party to the Treaty that launches or procures the launch of an object into outer space, including the moon and other celestial bodies, and each State Party from whose territory or facility an object is launched...'. Although the Outer Space Treaty contains these liability provisions, Articles VI and VII are neither comprehensive nor susceptible of precise application. Furthermore, the treaty does not establish an administrative or judicial tribunal to resolve space-related disputes and thus develops an effective system for conflict-resolution ${ }^{235}$. However, the Liability Convention that was adopted in 1972 supplements the guidelines under the Outer Space Treaty, and sets out detailed rules on claims procedure, compensation and liability of nations for damage caused by a launching state's space object.

\footnotetext{
${ }^{232}$ Wong, K.F. Collaboration in the Exploration of Outer Space: Using ADR to resolve conflicts in Space. Cardozo Journal of Conflict Resolution. 2006. Vol. 7, pp. 445 - 472 at p. 458.

${ }^{233}$ Governing the Commons: The Evolution of Institutions for Collective Action. Supra, note 2 at pp. $100-101$.

${ }^{234}$ Firestone, M.S. Problems in the Resolution of disputes concerning damage caused in space. Tulane Law Review. 1985, Vol. 59, pp. 747 - 780; Diedericks-Verchoor, I.H.Ph. and Gormley, W. P. The future legal status of nongovernmental entities in Outer Space: Private individuals and companies as subjects and beneficiaries of International Space Law. Journal of Space Law. 1997, Vol. 5, pp. 125 155; and Goh, G.M. 2007. Dispute Settlement in International Space Law: A Multi-Door Courthouse for Outer Space. Martinus Nijihoff Publishers: Leiden.

${ }^{235}$ Firestone. Ibid, p. 752.
} 
The Convention primarily deals with state responsibility, and so its compatibility challenges Ostrom's sixth principle. This is because the scope of parties allowed to invoke the treaty's provisions and be subject to claims of liability for damage caused by a space object are limited to nation-states. The defendant nationstate to such claims is the "launching state", defined under Article I(c) as a state which launches or procures the launching of a space object; or a state from whose territory or facility a space object is launched. The claimant nation-state, on the other hand, that may present to the launching state a claim for compensation for damage is not limited to the state of nationality. If the State of nationality has not presented a claim, another State may, in respect of damage sustained in its territory by any natural or juridical person, present a claim to a launching State. If neither the State of nationality nor the State in whose territory the damage was sustained has presented a claim or notified its intention of presenting a claim, another State may, in respect of damage sustained by its permanent residents, present a claim to a launching State $^{236}$. The Convention thus crystallises the classical doctrine of international law that states are subjects to international law and have locus standi to present claims before an international forum. Non-governmental entities are objects of international law with no means, or indeed legal right, for individuals to assert their claims at the international arena, and accordingly it is the claimant nation-state that must present the claim for damages on behalf of the non-state actors under its auspices ${ }^{237}$. However, it is incorrect to assume that it is the mandatory obligation upon the claimant state to approve, and so become a party to, the claim pursed by a private entity. Such outcome is at the discretion of that country as indicated by the word 'may' in Article VIII of the Liability Convention. By virtue Article VI of the Outer Space Treaty, that nation may prevent the non-governmental entity from proceeding with the claim if it determines that legal action undermine diplomatic relations or its efforts with another nation ${ }^{238}$. In such event, recourse would have to be taken at the domestic arena of the launching state where non-governmental entities retain their legal standing to assert their rights ${ }^{239}$.

The Liability Convention is applicable to disputes concerning damages caused by space objects in two limited scenarios, and the substantive basis of liability varies according to where damage is sustained. The first circumstance is provided in Article II which establishes that the launching State shall be absolutely liable for damage caused by its space objects on the surface of the earth or to aircraft in flight, except to the extent to which such damage has been caused by the gross negligence or an act or omission on the part of the victim or of the claimant State done with intent to cause damage $^{240}$. The second scenario is stated under Article III, providing that in the event of damage being caused elsewhere than on the surface of the Earth to a space object of one launching state or to persons or property on broad such a space object by a space object of another launching state, the latter shall be liable only if the damage is due to its fault or the fault of persons of whom it is responsible.

\footnotetext{
${ }^{236}$ Article VIII(2) and (3) of the Liability Convention.

${ }^{237}$ Diedericks-Verchoor, I.H.Ph. and Gormley, W. P. The future legal status of nongovernmental entities in Outer Space: Private individuals and companies as subjects and beneficiaries of International Space Law. Journal of Space Law. 1997, Vol. 5, pp. 125 - 155.

${ }^{238}$ Meek. Supra, note 131; and Listner, M. ROSAT and the Liability Convention. Space Review. October 17, 2011. Available from: http://www.thespacereview.com/article/1948/1. Date Accessed: $17 / 10 / 2010$.

${ }^{239}$ Article XI(2) of the Liability Convention.

${ }^{240}$ Article VI(1) of the Liability Convention.
} 
An innovative attribute of the Liability Convention which is consistent with Ostrom's principle 6 is that it establishes a system of alternative dispute resolutions. Article IX provides that a claim of compensation for damage shall be presented to a launching nation-state through diplomatic channels, first. If, however, settlements of a claim through diplomatic negotiations are not reached within one year from the date the claimant state presented the claim, arbitration procedures are then followed with either party being able to request a Claims Commission to be established. Articles $\mathrm{XV}$ through XX detail how the Commission is set up, the members forming it, and the procedures it is to follow, and the effect of its decision. Under Article XIX(2), the decision of the Commission is final and binding if the parties have so agreed.

Otherwise, the Commission shall be render a final and recommendatory award, which the parties shall consider in good faith. A scrutiny of the conflict-resolution mechanisms offered under the Liability Convention generates both positive and negative criticisms. On the one hand, the adoption of ADR procedures has the capacity to resolve space-related disputed in a peaceful and cooperative manner without litigation and adversarial confrontations that might otherwise breaking down or undermining diplomatic relations between sovereign nations. Such a positive feature of the system can be illustrated with the Soviet Cosmos 954 satellite incident in 1978 which settled the dispute for damages successful at the first stage of the claim; that is, through diplomatic negotiations. This event involved a threat of contaminating Earth's environment from radioactive material. Here, the Soviet satellite, using uranium as a source of fuel, re-entered Earth. This unscheduled reentry decayed the satellite but scattered radioactive remains landed on Earth. Majority of the debris was located in the Northwest of Canada which was inhabited. The affected territories had to undergo an extensive search and clean-up operation, and such expenses borne on the Canadian authorities exceeded one million Canadian dollars ${ }^{241}$. Canada presented a claim of damage for the sum of six million Canadian dollars to the Soviet Union under the Liability Convention. Consistent with Article IX, the states entered into diplomatic negotiations and, after a few sessions, settled the dispute with the Soviet Union agreeing to compensate Canada three million Canadian dollars in full and final settlement without recourse to the establishment of a Claims Commissions $^{242}$. Another positive point highlighted from this case study is that ' $[t]$ he fact that parties to settle rather than create a Claims Commission shows the responsible approach of the parties and how parties willing to reach an agreement will do so by compromise ${ }^{243}$. On the other hand, and perhaps justifies why state parties might be willing to settling the disputed upon first presentation of the claim, is that the outcome of the Claims Commission is merely a recommendatory award if parties agree not to be bound and thus must consider that award in good faith. For a binding decision, parties would have to seek redress under the municipal law of the launching state. This, in turn, questions the efficacy of the arbitration procedures under the Liability Convention if the Commission's decision is set aside altogether, and costly and time-consuming litigation and adversarial mechanisms are at any rate needed for compensation to be paid ${ }^{244}$.

\footnotetext{
${ }^{241}$ Cheng, B. Convention on International Liability for Damage Caused by Space Objects. In: Jasentuliyana, N. and R.S.K. Lee (eds). 1979. Manual on Space Law. Vol.1. Oceana Publications, Inc: New York. Chapter 3 at p. 84; and Viikari. Supra, note 2 at p. 48.

${ }^{242}$ Wong, Supra, note 232 at p. 463.

${ }^{243}$ Ibid, pp. $464-465$.

${ }^{244}$ Ibid, pp. $460-461$.
} 
Under the telecommunications regime, the ITU prescribes its conflict-resolution system for ITU members over disputes involving the allocation of GEO orbital slots and interference to radio communications. Under Article 56 of the ITU Constitution, member states may settle their disputes on questions relating to the interpretation or application of the ITU Constitution, of the ITU Convention or of the ITU Administrative Regulations (including Radio Regulations governing space communications) by negotiation, through diplomatic channels, or according to procedures established by bilateral or multilateral treaties concluded between them for the settlement of international disputes, or by any other method mutually agreed upon. If none of these methods of settlement is adopted, any Member State party to the dispute may have recourse to arbitration in accordance with the arbitration procedure as specified in Article 41 of the ITU Convention. Member States have also concluded an Optional Protocol on the Compulsory Settlement of Dispute Relating to ITU regulatory regime, which is applicable among member states to the protocol. This Protocol states that arbitration procedures as defined in Article 41 of the ITU Convention are compulsory for the settlement of disputes among state parties to the protocol. According to Jakhu, in practice, neither Article 41 of the Convention nor the Optional Protocol has been used ${ }^{245}$. All the harmful problems have been and are resolved in accordance to Article 15 of the Radio Regulations, which primarily deals with disputes through bilateral negotiations between the states concerned, and they are urged to "exercise the upmost goodwill and mutual assistance in the application of Article 45 of the Constitution and Article 15 of the Radio Regulations to settlement problems of harmful interference ${ }^{246}$. The ITU Radiocommunication Bureau may intervene but only if the state requires its services and any conclusion adopted is a non-binding recommendation, and accordingly highlights the 'voluntaristic norm' of the $\mathrm{ITU}^{247}$. That is to say, the Union lacks the competency to enforce its own rules and regulations over sovereign states through such formal mechanisms as sanctioning or coercive measures ${ }^{248}$.

From the above, there are therefore fundamental legal vacuums within the current dispute-resolution mechanisms under international space law. The ADR procedures under the Liability Convention are limited in their scope, covering only claims for compensation for damage caused by space objects on the surface of the Earth, or to aircraft in flight, or in outer space, and lack binding power to enforce the decision unless a specific agreement exists between the parties concerned ${ }^{249}$. The arbitration procedures under the ITU regime are also used in certain matters such as disputes involving the harmful interference to registered radio frequencies. For

\footnotetext{
245 Jakhu, R. Dispute resolution under the ITU agreements. Available from: http://swfound.org/media/48115/JakhuDispute\%20resolution\%20under\%20the\%20ITU\%20agreements.pdf. Date Accessed: 08/08/2011. ${ }^{246}$ Article 45 of the ITU Constitution read: 'All stations, whatever their purpose, must be established and operated in such a manner as not to cause harmful interference to the radio serices or communications of other Mmeberes or of recognized organised agencies, or of other duly authorized operating agencies which carru on a radio service, and which operate in accordance with the provisios of the Radio Regulations'. Article 15 of the ITU Radio Regulations reads: '(1) All stations are forbidden to carry out unnecessary transmission, or the transmission of superfluous signals, or the transmission of false or misleading signals, or the transmission of signals without identification (except as provided for in Article 19). (2) Transmitting stations shall radiate only as much power as is necessary to ensure a satisfactory service'.

${ }^{247}$ Vogler. Supra, note 21 at p. 114.

${ }^{248}$ Jakhu. Supra 124 at p. 181; and Dispute resolution under the ITU agreements. Supra, note 244.

${ }^{249}$ Judge Pocar, F. An Introduction to the PCA's Optional Rules for Arbitration of Disputes Relating to Outer Space Activities. Journal of Space Law. 2012, Vol. 38, pp. 171 - 185 at p.176.
} 
disputes outside the matters covered by the outer space and telecommunication regimes, respectively, there is no other outer space specific means of conflictresolution for nation-states to consider ${ }^{250}$. Furthermore, the dispute-resolution systems under international space law were envisaged to only be used by states: private entities do not have direct access to these forums. In light of the diversification and intensification of space activities and non-state space actors, the space community has recently recognised that not only the number of space-related disputes would arise but such disputes 'can arise between states, states agencies, intergovernmental, regional or international organizations, and private entities, such as national and multinational corporations. With the advent of space tourism, even private persons may become entangled in disputes relating to outer space activities ${ }^{251}$. To that end, on December 6, 2011, the Administrative Council of the Permanent Court of Arbitration (PCA) adopted the Optional rules for Arbitration of Disputes Relating to Outer Space Activities (Outer Space Rules) as an effort to address the problems with the current dispute-resolution system by providing a means of voluntary and binding dispute resolution available to all parties - state and non-state - engaged in outer space activities and tailored to the particularities of this unique area of economic activity $^{252}$. The PCA is an intergovernmental organisation with 115 member states that have acceded to its founding conventions. It was established through the 1899 Convention for Pacific Settlement of International Disputes and the 1907 Convention for the Pacific Settlement of International Disputes. One of the PCA's purpose is to provide forum for arbitration and other forms of dispute resolution between various combinations of states, state entities, intergovernmental organisations, and private parties. The Outer Space Rules are based on the 2010 United Nations Commission on International Trade Law (UNICITRAL) Arbitration Rules and have been adapted to provide a set of specialised arbitration rules for disputes arising from the space sector. The Rules reflect the particular characteristics of disputes having an outer space component involving the use of outer space by States, international organizations and private entities; and reflect the public international law element that pertains to disputes that may involve States and the use of outer space, and international practice appropriate to such disputes. They establish the jurisdiction of the PCA to arbitrate and specifying the authority of Secretary-General of the PCA at The Hague.

Moreover, the Outer Space Rules providing the parties the freedom to choose an arbitral tribunal composed of one, three, or five persons; provide a specialised list of arbitrators with specialised competencies within the field of outer space and a list of scientific and technical experts to address technical issues that may be pertinent to a dispute; and provide suggestions for establishing procedures at ensuring confidentiality. The Rules are optional and emphasise flexibility and party autonomy. For example, the Rules, and the services of the Secretary-General and the PCA, are available to states, international organizations, and private parties. Also, they may be used in relation to disputes two or more States parties to a multilateral agreement relating to the use of or access to outer space concerning the interpretation or application of that agreement ${ }^{253}$. Judge Pocar, who chaired the Advisory group which

\footnotetext{
${ }^{250}$ Listner, M. A new paradigm for arbitrating disputes in outer space. The Space Review. January $9^{\text {th }}$, 2012. Available from: http://www.thespacereview.com/article/2002/1. Date Accessed: 09/01/2012.

${ }^{251}$ Judge Pocar. Supra, note 249 at p. 175.

${ }^{252}$ Ibid, p. 171.

${ }^{253}$ Permanent Court of Arbitration. Optional Rules for Arbitration of Disputes relating to Outer Space Activities. December 6, 2011. Available from: http://www.pca-cpa.org/showfile.asp?fil_id=1774. Date Accessed: 06/12/2011.
} 
drafted the Outer Space Rules, takes the view that such flexibility and voluntary mechanisms of the arbitration procedures is important where states are involved, as it may incentivise them to agree to binding dispute resolution under discrete agreements than to enter into a new significant to enter into new significant multilateral treaty to the effect that all space-related disputes are dealt in an universal and invariable way $^{254}$. Unlike the Liability Convention which provides recommendatory decisions if parties do not agree to be bound, arbitration outcomes are final and binding. There are no appeals and only limited grounds for challenges are available. As Judge Pocar states: 'This can be of great importance given that space activities often operate on precise and fixed schedules, especially as regards to the time windows for landing, atmospheric re-entry, descent and landing, and orbit insertion. In these situations, only swiftly-obtained final decisions are of any value ${ }^{255}$. A novel addition to the Outer Space Rules sets forth a model clause for arbitration of existing and future disputes for parties to consider inserting or modifying into treaties or contracts. The purpose of arbitration clause is indicate the express intent of parties to settle any dispute, controversy or claim arising from the contract or treaty through arbitration in accordance with the PCA's Outer Space Rules.

The recent emergence of the PCA's Outer Space Rules highlights the space community's efforts to develop a comprehensive dispute-resolution system that has the capacity to adapt to the maturing space industry; hereby alleviating the failures of the current body of international space law. The significance of the Rules goes beyond than providing a viable forum that is accessible to both state and non-state actors to resolve outer space-related disputes through ADR procedures. It also has the potential to promote confidence within the members of the space community that ruleinfractions and other types of conflicts would be swiftly and competently settled to ensure that existing and planned space operations are not affected or postponed, and that development of the space sector is not stifled. With this in mind, it is suggested that under the proposed alternative institutional arrangement for outer space entrenches the PCA's Outer Space Rules as its conflict-resolution mechanisms.

\subsubsection{Principle 7: Minimal recognition of rights to organise}

Principle 7 provides that external governmental authorities permit and do not challenge the rights of appropriators to devise their own institutions. Providing that the external governmental agencies give a least minimal recognition to the legitimacy of such rules, resource users themselves may be able to enforce the rules themselves. Ostrom, however, warns, that if external governmental officials presume that only they have the authority to set the rules, then it will be very difficult for local appropriators to sustain a rule governed CPR over the long run. In a situation in which one wishes to get around the rules created by the appropriators, one may go to the external government and try to get local rules overturned ${ }^{256}$.

Ostrom's seventh design principle echoes the concept of institutional legitimacy under the literature of organizational theory ${ }^{257}$. Here, 'legitimacy' has both a

\footnotetext{
${ }^{254}$ Judge Pocar. Supra, note 249 at p. 171.

${ }^{255}$ Ibid, p. 178.

${ }^{256}$ Governing the Commons: The Evolution of Institutions for Collective Action. Supra, note 3 at p. 101.

${ }^{257}$ See, for example: Suchman, M.C. Legitimacy: Strategic and Institutional Approaches. The Academy of Management Review. 1995, Vol. 20(3), pp. 571 - 610; and Buchanan, A. and R.O. Keohane. The
} 
normative and a sociological meaning. In the normative sense, a legitimate institution can assert it right to rule; that is, to make rule-making outcomes, adopt mechanisms to assure rule-compliance and enforce sanctions against rule-breakers. An institution is legitimate in the sociological sense when it is widely believed to have the right to rule. If the institution lacks legitimacy, then it claim to authority is unfounded and it is not entitled to on-going support and compliance from state and non-state actors ${ }^{258}$. Ostrom's empirical studies suggest that legitimacy of local CPR institutions are not too difficult to establish, but the same might not hold true for those international institutions whose governance activities are carried out by both state and non-state actors $^{259}$. With this in mind, it is assumed that the proposed Association of Space Appropriators has institutional legitimacy to regulate the use and exploration of outer space and oversee access and the activities of state and non-state space actors, and recommend that further research is required to examine the theoretical strategies to determine if the ASA can gain and, if so, maintain its legitimacy as a global governance institution.

\subsubsection{Principle 8: Nested enterprises for larger, complex CPRs}

The final design principle under Ostrom's framework for institutional arrangement is that the appropriation, provision, monitoring, enforcement, conflict resolution, and governance activities are organised in multiple layers of nested enterprises ${ }^{260}$. In other words, Principle 8 recommends a polycentric governance system for larger, complex interactive resource CPRs. As explained above, this multilayered institutional arrangement fosters a co-management arrangement whereby authority over regulating access and use of the commons resource is vested to more than one entity, and does not exclude resource stakeholders like individuals, communities and non-governmental organisations from working cooperatively with regional authorities and national governments to tackle overexploitation and misuse. It also means that there is room for different types of environmental regulations such as command-and-control, market-based regulations and soft laws to influence the governance of global resources. However, as Stern states, the challenge is to find combination of institutional forms that can effectively implement the other design principles $^{261}$. According to the commons literature, the success of polycentric management is determined by the linkages, or nesting, among the pre-existing institutions with responsibilities for managing parts of the system and the communications between them for information affecting their respective part of commons and in turn the resource system as a whole $\mathrm{e}^{262}$.

The existing space governance regime are organised in a polycentric system, As seen above, there are two levels where collective and operational choice outcomes are

legitimacy of Global Governance Institutions. Ethics \& International Affairs. Vol. 20(4), pp. 405 437.

${ }^{258}$ Buchanan and Keohane. Ibid, pp. 405 and 407.

${ }^{259}$ Stern. Supra, note 105 at p. 222.

${ }^{260}$ Governing the Commons: The Evolution of Institutions for Collective Action. Supra, note 2 at pp. $101-102$.

${ }^{261}$ Stern. Supra, note 105 at p. 224.

${ }^{262}$ Governing the Commons: The Evolution of Institutions for Collective Action. Supra, note 2 at $\mathrm{p}$. 101; and Stern, P.C. T. Dietz., N. Dolšak., E. Ostrom., and Stonich, S. Knowledge and Questions After 15 Years of Year. In: The Drama of the Commons. Committee on the Human Dimensions of Global Change. Ostrom,. E., T. Dietz., N. Dolšak., P.C. Stern., S. Stonich., Weber, E.U. (eds). 2002. National Academy Press: Washington, D.C. Chapter 13, pp. 445 - 489 at p. 463. 
produced - the international and national arenas. It, however, would be incorrect to assume that this intuitional arrangement satisfies Ostrom's eighth design as its success and robustness in governing outer space is doubted. It is argued that, owing to the polycentric system, the existing space governance regime is inadequacy to regulate the use and exploration of the orbits and oversee the activities of space actors, and to address such collection action problems as space debris for the long-term safety and sustainable of the space environment. A paradox emerges the international plane; that is, there are two different legal regimes operating concurrently to govern and manage the same resource system - the 'outer space regime' and 'telecommunications regime'. However, the institutional linkage among the international bodies responsible for the Space Commons is absence. The efforts from the ITU have little to do with the overarching provisions of the Outer Space Treaty. By the same token, the five space treaties have little operation for the regulation and management of the radio frequency spectrum ${ }^{263}$. Communication, or interplay, between the two regimes is also lacking to the extent that it not resulted only in a fragmented legal regime for outer space activities but has too endangered the unity and coherence of international space law because of competing provisions within the space treaties and ITU regulations ${ }^{264}$. The lack of interplay between the international institutions become apparent by the 1976 Bogotá Declaration $^{265}$, where developing countries party to the agreement at COPUOS attempted to treat the ITU technical regulations as de facto international space law in order to assert preferential rights in the allocation of orbital positions in GEO above their respective national territories ${ }^{266}$. Taking the sum of these two international governance systems shows that there is not only a fragmented regime for space, but they lack the competency to address commons problems such as orbital debris which affect resource users regulated under either the outer space or telecommunications regime ${ }^{267}$.

By virtue of Article VI of the Outer Space Treaty and the ITU Radio Regulations, there is cross-scale institutional interplay between the first (international) and second (national) collective-choice levels. As a result, there are many institutions constantly interacting with one another both "horizontally" or at the same scale or level of social organisation, and "vertically" or across level of social organisation 268 . The resultant interaction among these institutions may generate consequences which affect the performance of an individual institution and robustness to deal with commons- related problems such as environmental degradation ${ }^{269}$. Owing to this bifurcated arrangement, it is argued that the problems and weaknesses with the international governance arrangement for space designed at the international plane are mirrored in the regime formation processes created by nation-states at the national

\footnotetext{
${ }^{263}$ Young, O.R. Governing International Spaces: Antarctica and Beyond. pp. $287-294$ at p. 293. In: Berkman, P.A., M.A. Lang., D.W. H. Walton, and O.R. Young (eds). 2011. Science Diplomacy: Science, Antarctica, and the Governance of International Spaces. Smithsonian Institution Scholarly Press.

${ }^{264}$ Danilenko. Supra, note 165 at p. 239.

${ }^{265}$ Declaration of the First Meeting of the Equatorial States, Bogotá, December 3, 1976. Journal of Space. 1978, Vol. 6, pp. 193 - 196.

${ }^{266}$ Danilenko. Supra, note 165 at p. 239.

${ }^{267}$ Governing International Spaces: Antarctica and Beyond. Supra, note 264 at p. 293.

${ }^{268}$ Young, O.R. Institutional Interplay: The Environmental Consequences of Cross-Scale Interactions. Chapter 8, pp. 263 - 291 at pp. 263 - 264. In: The Drama of the Commons. Committee on the Human Dimensions of Global Change. Ostrom,. E., T. Dietz., N. Dolšak., P.C. Stern., S. Stonich., Weber, E.U. (eds). 2002. National Academy Press: Washington, D.C.

${ }^{269}$ Ibid, p. 263.
} 
arena. This is because, as aforesaid, international instruments and other outcomes created in CD, COPUOS and ITU are however subject to the autonomous choice of spacefaring state actors to adopt these measures into their domestic legal systems. Furthermore, treaty provisions such as Article VI of the Outer Space Treaty are framed in terms that are sufficiently generic to allow an individual member state a wide margin of appreciation to design and implement a regime in a manner it chooses and that is consistent with legal traditions prevailing in that country ${ }^{270}$. Such topbottom interactions means that individual states would have had implemented at least two regulatory regimes in its legal systems in order to give effect to its international obligations as prescribed under the 'outer space' and 'telecommunications' regimes. Across the second collective-choice level, there is no single national arena that is responsible for the development of collective rules, including the implementation of the international regimes into the domestic legal systems of spacefaring and spacecapable states, and the policing of space activities by commercial and private space launchers. Moreover, the exclusion of the commercial space sector from membership to the international bodies responsible for the governance of space at the constitutional-choice level means that non-governmental users of outer space are excluded from participating in the formation, revision and implementation of the rules used to create the operational- choice rules. The only arenas for collective-choice outcomes are external to actual users of space. Individual states delegate rule and decision-making authority to external entities outside the space community that do not directly generate benefits from the appropriation and utility of space and its resources. It is argued that the resultant consequence of such institutional linkage between the international and national arenas is the danger of haphazard and perverse decisionmaking outcomes. Legislators and administrators may act opportunistically, taking decisions that ignore, or even contradict, the international agreements on space in order in order to maximise their utility of space and the benefits derived at the expense of the collective aim for the efficient usage of space and the minimise interference to other users' current and planned missions ${ }^{271}$. To that end, domestic legal frameworks may undermine and possibly be asymmetrical to international space law, and thus lead to considerable variance of performance among individual spacefaring nations when it comes to fulfilling their international obligations. It is argued that such variance in performance between member states at the national arena, where heterogeneity already exists, is an additional barrier which substantially challenges the overall robustness of the 'outer space' and 'telecommunications' regimes to collectively promote the long-term management and environmental sustainability of space and encourage international cooperation between state actors to address common problems such as space congestion.

In light of the institutional analysis performed on the existing space governance regime, a polycentric approach for an alternative institutional arrangement to govern outer space should not be avoided. As Stern stated above, the challenge is finding the institutional form that can effectively implement the other design principles ${ }^{272}$. By applying Ostrom's eighth principle to outer space, a co-management arrangement with state and non-state space actors forming an Association of Space Appropriators should be organised. To effectively implement the other design principles, a

\footnotetext{
${ }^{270}$ Ibid, pp. 277 - 278. See also: Telecommunications Management Group, Inc. Legal and Institutional Aspects of Regulation. Module 6 of the ICT Regulation Toolkit at pp. 16 - 25. November 2006. Available from: http://www.ictregulationtoolkit.org/en/Section.1254.html. Date Accessed: 09/12/2012. ${ }^{271}$ Lyall. Supra, note 161.

${ }^{272}$ Stern. Supra, note 105 at p. 224.
} 
monocentric approach is suggested. In other words, the development and revision of collective-choice rules; monitoring and enforcement; dispute resolution; and other governance activities are carried out in a single arena.

\subsection{Conclusion}

To conclude, Ostrom's framework for institutional arrangement can be applied to near-Earth orbits to design an appropriate and feasible alternative governance system to regulate the Space Commons. However, the original design principles that were created from lessons learnt from empirical studies on local, small-scale CPRs require adjustments to overcome certain challenges which occur during the scaling-up process to a larger-scale, extraterrestrial commons. Setting clearly defined boundaries of the rules the commons itself is not a relevancy exercise for space. This is because space is and part of a complex, interactive resource system. A satellite operator, for instance, would access and pass the two other commons - the Airspace Commons and the Near-Space Commons, before accessing the Space Commons and utilising the radio frequencies spectrum in GEO. Furthermore, the delimitation of airspace and outer space is now an academic exercise given the recent development of reusable launch vehicles which have hybrid technological capabilities as civilian aircrafts and spacecrafts. However, there must be clear rules defining the individuals who are eligible to enter space and have appropriation rights. In light of the diversification and intensification of space actors, especially non-state users from the commercial space sector and private entities, an Association of Space Appropriator (ASA) should be incorporated. Membership to this Association is based on certain requirements that must be satisfied before membership to the ASA can be considered. Such membership test can potentially limit the scope of space actors who eligible access and use space to promote its optimal and sustainable management by excluding irresponsible actors. The Association is the single regulator that governs the use and exploration of outer space and oversees access and the activities of the space appropriators. Accordingly, the ASA is vested authority to develop and revise the collective-choice rules which are congruent to the peculiar characteristics of the space and its changing environment, and make other decision-making outcomes. It is also responsible to ensure rule-compliance, enforcing its rules with the use of an appropriate system of graduated sanctioning against rule-breakers, and resolving space-related disputes by following the PCA's Outer Space Rules. However, the detection of such noncompliance would lie with an independent, external monitoring agency that provides space surveillance services and effectively shares SSA data to all space appropriators, and thus avert concerns that nation-states with SSNs conceal information for reasons of national security. This co-management arrangement for the Space Commons is based on a monocentric system, not polycentric. Eligible states and non-state space actors form the ASA and carry out its governance activities under a single arena. It is hoped that such institutional design would yield a robust and sustainable governance system that optimally addresses collective-action problems such as space congestion to foster the long-term environmental preservation and safety of near-Earth orbits for existing and future space appropriators. 